\title{
. \\ Metal Complexes of the Porphyrin-Functionalized Polybenzoxazine
}

\author{
Guohu Zhang ${ }^{1}$, Ahmed F. M. EL-Mahdy ${ }^{1}{ }^{\mathbb{D}}$, Lamiaa Reda Ahmed ${ }^{1,2}{ }^{2}$ Babasaheb M. Matsagar ${ }^{3}$,
} Sameerah Al-Saeedi ${ }^{4}$, Shiao-Wei Kuo ${ }^{1,5, *(D)}$ and Kevin C.-W. Wu ${ }^{3,6, *(D)}$

check for

updates

Citation: Zhang, G.; EL-Mahdy, A.F.M.; Ahmed, L.R.; Matsagar, B.M.; Al-Saeedi, S.; Kuo, S.-W.; Wu, K.C.-W. Metal Complexes of the PorphyrinFunctionalized Polybenzoxazine. Polymers 2022, 14, 449. https:// doi.org/10.3390/polym14030449

Academic Editor: Asterios (Stergios) Pispas

Received: 10 December 2021

Accepted: 20 January 2022

Published: 23 January 2022

Publisher's Note: MDPI stays neutral with regard to jurisdictional claims in published maps and institutional affiliations.

Copyright: (C) 2022 by the authors. Licensee MDPI, Basel, Switzerland. This article is an open access article distributed under the terms and conditions of the Creative Commons Attribution (CC BY) license (https:// creativecommons.org/licenses/by/ $4.0 /)$.
1 Center for Functional Polymers and Supramolecular Materials, Department of Materials and Optoelectronic Science, National Sun Yat-Sen University, Kaohsiung 80424, Taiwan; m083100049@student.nsysu.edu.tw (G.Z.); ahmedelmahdy@mail.nsysu.edu.tw (A.F.M.E.-M.); d102060004@student.nsysu.edu.tw (L.R.A.)

2 Institute of Medical Science and Technology, National Sun Yat-Sen University, Kaohsiung 80424, Taiwan

3 Department of Chemical Engineering, National Taiwan University, No. 1, Sec. 4, Roosevelt Road, Taipei 10617, Taiwan; matsagar03@ntu.edu.tw

4 Department of Chemistry, College of Science, Princess Nourah Bint Abdulrahman University, Riyadh 11671, Saudi Arabia; sialsaeedi@pnu.edu.sa

5 Department of Medicinal and Applied Chemistry, Kaohsiung Medical University, Kaohsiung 80708, Taiwan

6 International Graduate Program of Molecular Science and Technology, National Taiwan University (NTU-MST), No. 1, Sec. 4, Roosevelt Road, Taipei 10617, Taiwan

* Correspondence: kuosw@faculty.nsysu.edu.tw (S.-W.K.); kevinwu@ntu.edu.tw (K.C.-W.W.)

Abstract: New porphyrin-functionalized benzoxazine (Por-BZ) in high purity and yield was synthesized in this study based on ${ }^{1} \mathrm{H}$ and ${ }^{13} \mathrm{C}$ NMR and FTIR spectroscopic analyses through the reduction of Schiff base formed from tetrakis(4-aminophenyl)porphyrin (TAPP) and salicylaldehyde and the subsequent reaction with $\mathrm{CH}_{2} \mathrm{O}$. Thermal properties of the product formed through ring-opening polymerization (ROP) of Por-BZ were measured using DSC, TGA and FTIR spectroscopy. Because of the rigid structure of the porphyrin moiety appended to the benzoxazine unit, the temperature required for $\operatorname{ROP}\left(314^{\circ} \mathrm{C}\right)$ was higher than the typical Pa-type benzoxazine monomer (ca. $\left.260{ }^{\circ} \mathrm{C}\right)$; furthermore, poly(Por-BZ) possessed a high thermal decomposition temperature $\left(T_{\mathrm{d} 10}=478{ }^{\circ} \mathrm{C}\right)$ and char yield $(66 \mathrm{wt} \%)$ after thermal polymerization at $240{ }^{\circ} \mathrm{C}$. An investigation of the thermal and luminescence properties of metal-porphyrin complexes revealed that the insertion of $\mathrm{Ni}$ and $\mathrm{Zn}$ ions decreased the thermal ROP temperatures of the Por-BZ/Ni and Por-BZ/Zn complexes significantly, to 241 and $231{ }^{\circ} \mathrm{C}$, respectively. The metal ions acted as the effective promoter and catalyst for the thermal polymerization of the Por-BZ monomer, and also improved the thermal stabilities after thermal polymerization.

Keywords: polybenzoxazine; ring-opening polymerization; porphyrin; metal complex; thermal stability

\section{Introduction}

The chemistry of benzoxazines (BZs) has attracted much interest for two decades now, owing to their potential applications in coatings, composites, and electronics [1-6]. The thermal ring-opening polymerizations (ROPs) of BZ monomers result in highly cross-linked structures, formed as a result of Mannich condensations of phenolic and formaldehyde derivatives with primary amines [7-13]. Because strong inter- and intramolecular hydrogen bonds exist after the thermal ROP of BZ units, formed among the tertiary amino and phenolic units in the Mannich bridges, the polymerization products can possess low dielectric constants, low surface free energies, low degrees of shrinkage, and high thermal stabilities and char yields [14-20]. Flexibility in molecular design-by varying the structures of the phenolic and amino groups-has allowed the introduction of a range of functional groups 
(e.g., allyl, propargyl, crown ether) [21-31] or inorganic nanomaterials (such as polyhedral oligomeric silsesquioxane, graphene, carbon nanotube) [32-41] into the BZ matrix.

Porphyrin is a molecular material with many potential applications; for example, because of its unique magnetic, photophysical, and electronic properties, it has been integrated in light-energy conversion systems [42-45]. This colored macrocycle possesses particularly attractive photophysical properties, including very high extinction coefficients in the near-IR and visible regions where the solar photon flux occurs, making it useful in redox chemistry, photo-harvesting, semiconductors, and photoinduced electron transfer [46,47]. Various porphyrin-functionalized polymers have been prepared, usually connected with metal ions or reactive units [48-50]. Based on several previous reports [41-49], in this study, the synthesis and ROP of a porphyrin-functionalized benzoxazine (Por-BZ) monomer were investigated; to the best of our knowledge, such structures have not been described previously.

We synthesized Por-BZ through a Schiff base formation from tetrakis(4-aminophenyl) porphyrin (TAPP) and salicylaldehyde and subsequent treatment for $o$-hydroxybenzylamine derivative with $\mathrm{CH}_{2} \mathrm{O}$ (Scheme 1). Fourier transform infrared (FTIR) and nuclear magnetic resonance (NMR) spectroscopy were used to confirm the chemical structure of Por-BZ; we then employed differential scanning calorimetry (DSC), FTIR spectroscopy, and thermogravimetric analysis (TGA) to determine the thermal ROP behavior of Por-BZ and its thermal stability in the presence of $\mathrm{Ni}$ and $\mathrm{Zn}$ ions. Furthermore, we used UV-Vis and photoluminescence (PL) spectroscopy to examine the luminescence properties of TAPP, Por-BZ, and Por-BZ/metal ion complexes.
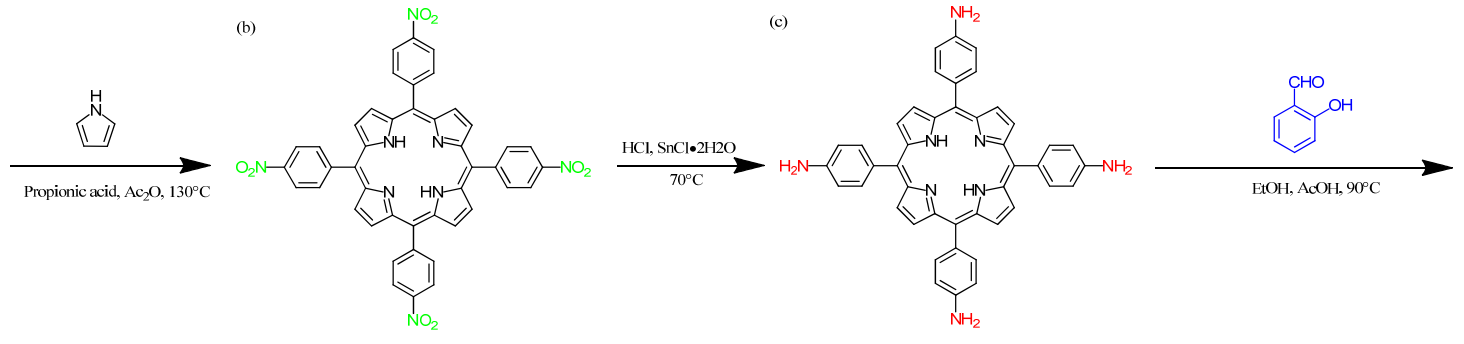

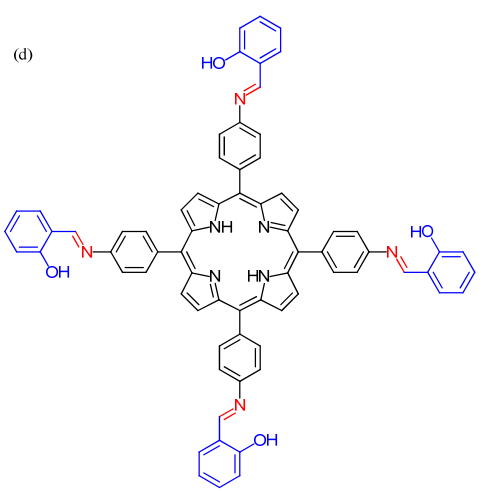

Porphyrin-salicylaldehyde

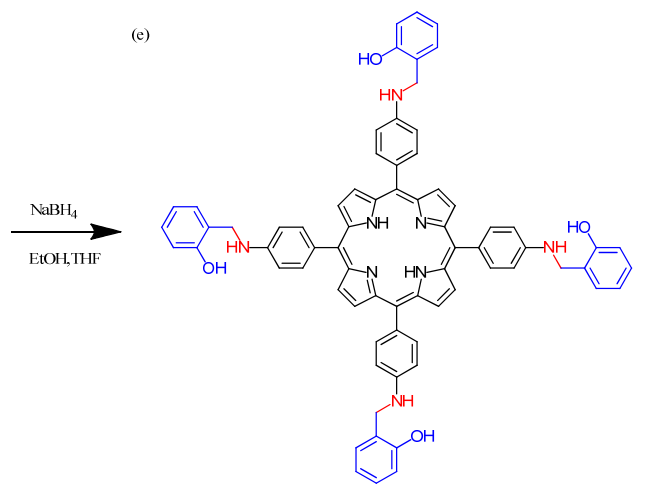

Porphyrin-hydroxybenzylamine

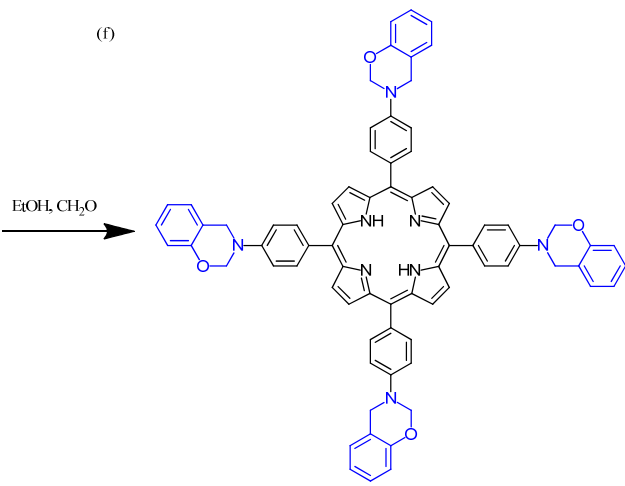

Porphyrin-Benzoxazine (Por-BZ)

Scheme 1. Synthesis of (f) Por-BZ monomer from (a) 4-nitrobenzaldehyde, (b) TNPP, (c) TAPP, (d) Por-Sa, and (e) Por-Hy.

\section{Experimental Section}

\subsection{Materials}

Pyrrole (99.5\%), 4-Nitrobenzaldehyde (99\%), salicylaldehyde (99\%), EtOH (99.9\%), acetic acid (99.8\%), formaldehyde, hexane (99\%), and N,N-dimethylformamide (DMF, 99.5\%) were purchased from Acros (Taipei, Taiwan). Propionic acid (99.5\%), acetic anhydride (99\%), tetrahydrofuran (THF, 99\%) $\mathrm{MeOH}(99 \%)$, pyridine (99\%), hydrochloric acid, 
and chloroform (99.9\%) were purchased from Sigma-Aldrich (Taipei, Taiwan). $\mathrm{SnCl}_{2} \cdot 2 \mathrm{H}_{2} \mathrm{O}$ $(99 \%)$, zinc acetate dihydrate (99\%), and nickel acetate dihydrate (99\%) were purchased from Showa (Kaohsiung, Taiwan) and used without purification.

\subsection{5,10,15,20-Tetrakis(4-Aminophenyl)Porphyrin (TAPP)}

Propionic acid $(80 \mathrm{~mL}), 4-N i t r o b e n z a l d e h y d e ~(3.0 \mathrm{~g}, 0.020 \mathrm{~mol})$, and acetic anhydride $(3.2 \mathrm{~mL}, 0.034 \mathrm{~mol})$ were heated to $130{ }^{\circ} \mathrm{C}$ in a three-neck round-bottom flask, and then pyrrole $(1.38 \mathrm{~mL}, 0.020 \mathrm{~mol})$ was added dropwise via syringe. After heating under reflux for $1 \mathrm{~h}$, the mixture was cooled to room temperature to obtain a black precipitate, which was collected by filtration and washed three times with $\mathrm{MeOH}$. The black solid was dissolved in pyridine $(100 \mathrm{~mL})$ and heated under reflux at $110^{\circ} \mathrm{C}$ for $4 \mathrm{~h}$; the mixture was placed in a refrigerator overnight. The precipitate was collected by filtration and washed three times with $\mathrm{MeOH}$. This product was dried under vacuum at $80{ }^{\circ} \mathrm{C}$ for $24 \mathrm{~h}$ to give tetrakis $(4-$ nitrophenyl)porphyrin (TNPP) as purple microcrystals (yield: 15\%). A solution of TNPP $(0.60 \mathrm{~g}, 0.76 \mathrm{mmol})$ in concentrated $\mathrm{HCl}(36.5 \%, 40 \mathrm{~mL})$ was heated up to $70{ }^{\circ} \mathrm{C}$ in a two-neck flask, then $\mathrm{SnCl}_{2} \cdot \mathrm{H}_{2} \mathrm{O}(4.5 \mathrm{~g}, 200 \mathrm{mmol})$ was added. The mixture was stirred at $70{ }^{\circ} \mathrm{C}$ for $2 \mathrm{~h}$ and then cooled to $0{ }^{\circ} \mathrm{C}$. After neutralization with aqueous $\mathrm{NH}_{3}$, the gray product was collected by filtration and dissolved in THF. After ultrasonication, the mixture was filtered to remove any insoluble materials and then the filtrate was concentrated (rotary evaporation) and dried under vacuum to yield TAPP as violet crystals (yield: $80 \%$ ).

\subsection{Porphyrin-Salicylaldehyde (Por-Sa)}

A solution of TAPP $(0.50 \mathrm{~g}, 0.74 \mathrm{mmol})$ and salicylaldehyde $(0.48 \mathrm{~mL}, 4.5 \mathrm{mmol})$ in EtOH $(70 \mathrm{~mL})$ and acetic acid $(99.8 \%, 1 \mathrm{~mL})$ was heated at $90^{\circ} \mathrm{C}$ for $4 \mathrm{~h}$ under reflux. The solid was filtered off after cooling, washed with $\mathrm{EtOH}$, and dried under vacuum $\left(70{ }^{\circ} \mathrm{C}\right.$, $12 \mathrm{~h}$ ) to obtain porphyrin-salicylaldehyde as a purple solid (yield: 57\%).

\subsection{Porphyrin-Hydroxybenzylamine (Por-Hy)}

A mixture of Por-Sa $(0.80 \mathrm{~g}, 1.7 \mathrm{mmol})$, sodium borohydride (300 mg, $6.7 \mathrm{mmol}), \mathrm{EtOH}$ $(40 \mathrm{~mL})$ and dry THF $(16 \mathrm{~mL})$ was stirred in a $100-\mathrm{mL}$ three-neck flask for $24 \mathrm{~h}$ at $25{ }^{\circ} \mathrm{C}$. The resulting solution was concentrated (rotary evaporation) until the volume had halved. This dark-green solution was poured into ice water in a 500-mL beaker and then stirred. After filtration and washing with deionized water, the Por-Hy was dried under vacuum $\left(70{ }^{\circ} \mathrm{C}, 12 \mathrm{~h}\right)$ to provide porphyrin-hydroxybenzylamine (yield: $40 \%$ ).

\subsection{Porphyrin-Salicylaldehyde-Benzoxazine (Por-BZ)}

A mixture of Por-Hy $(0.70 \mathrm{~g}, 0.64 \mathrm{mmol})$, THF $(10 \mathrm{~mL})$, absolute EtOH $(60 \mathrm{~mL})$, and paraformaldehyde $(2 \mathrm{~mL}, 7.3 \mathrm{mmol})$ was stirred in a $100-\mathrm{mL}$ three-neck flask at $90{ }^{\circ} \mathrm{C}$. Periodically, a drop of the reaction mixture was placed in a small amount of THF and thin layer chromatography (THF/hexane, 1:1) was used to monitor the reaction. After $24 \mathrm{~h}$, the solid was filtered off, washed with $\mathrm{EtOH}$, and dried under vacuum $\left(70{ }^{\circ} \mathrm{C}, 12 \mathrm{~h}\right)$ to obtain Por-BZ as a purple powder (yield: $85 \%$ ).

\subsection{Por-Benzoxazine-Nickel(II) and-Zinc(II) Complexes (Por-BZ/Ni and Por-BZ/Zn)}

Por-BZ (100 mg, $0.087 \mathrm{mmol}), \mathrm{DMF}(20 \mathrm{~mL})$, and $\mathrm{CHCl}_{3}(45 \mathrm{~mL})$ were placed in a flask. $\mathrm{Ni}(\mathrm{OAc}) 2 \cdot 4 \mathrm{H}_{2} \mathrm{O}(150 \mathrm{mg}, 0.6 \mathrm{mmol})$ (or $\mathrm{Zn}(\mathrm{OAc})_{2} \cdot 2 \mathrm{H}_{2} \mathrm{O}(130 \mathrm{mg}, 0.6 \mathrm{mmol})$ ) was dissolved in $\mathrm{MeOH}(20 \mathrm{~mL})$; after ultrasonication, it was added dropwise into the reaction mixture, which was then heated at $60{ }^{\circ} \mathrm{C}$ for $24 \mathrm{~h}$. Then, the solution was partitioned between $\mathrm{H}_{2} \mathrm{O}$ and $\mathrm{CHCl}_{3}$ after cooling to $25^{\circ} \mathrm{C}$; the organic phase was washed twice with brine, dried, and concentrated (rotary evaporation). The residual DMF was evaporated through vacuum distillation $\left(60-70{ }^{\circ} \mathrm{C}, 1 \mathrm{~h}\right)$. THF $(20 \mathrm{~mL})$ was added to the residue. After rotary evaporation and drying under vacuum $\left(70{ }^{\circ} \mathrm{C}, 12 \mathrm{~h}\right.$ ), Por-BZ/Ni (or Por-BZ/Zn) was obtained (yield: $48 \%$ ) as shown in Scheme 2. 
(a)

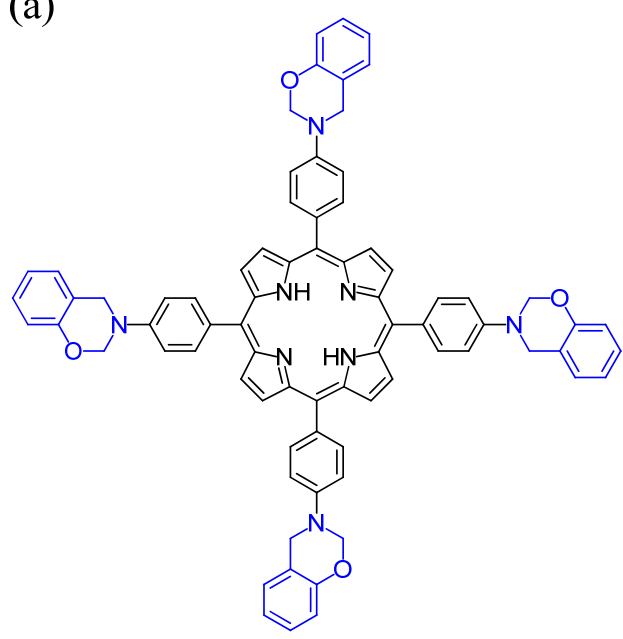

Porphyrin-Benzoxazine (Por-BZ) (b)

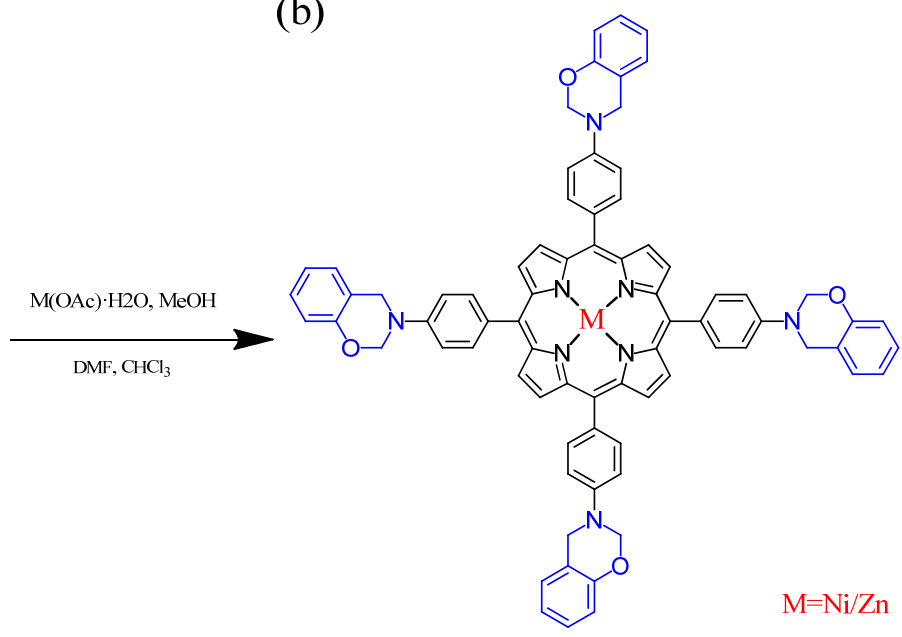

Por-BZ/Metal

Scheme 2. Chemical structures of (a) Por-BZ and (b) the Por-BZ/metal complexes.

\subsection{Polymerization of BZ Monomer}

The Por-BZ monomer underwent thermally ring-opening polymerization by heating at $150,180,210,240,270$, and $300^{\circ} \mathrm{C}(2 \mathrm{~h}$ at each temperature $)$ in a stepwise manner. In the same manner, Por-BZ/Ni and Por-BZ/Zn were also subjected to thermal polymerization by heating at 150,180,210, and $240{ }^{\circ} \mathrm{C}$; they were at each temperature for $2 \mathrm{~h}$ (Scheme 3).
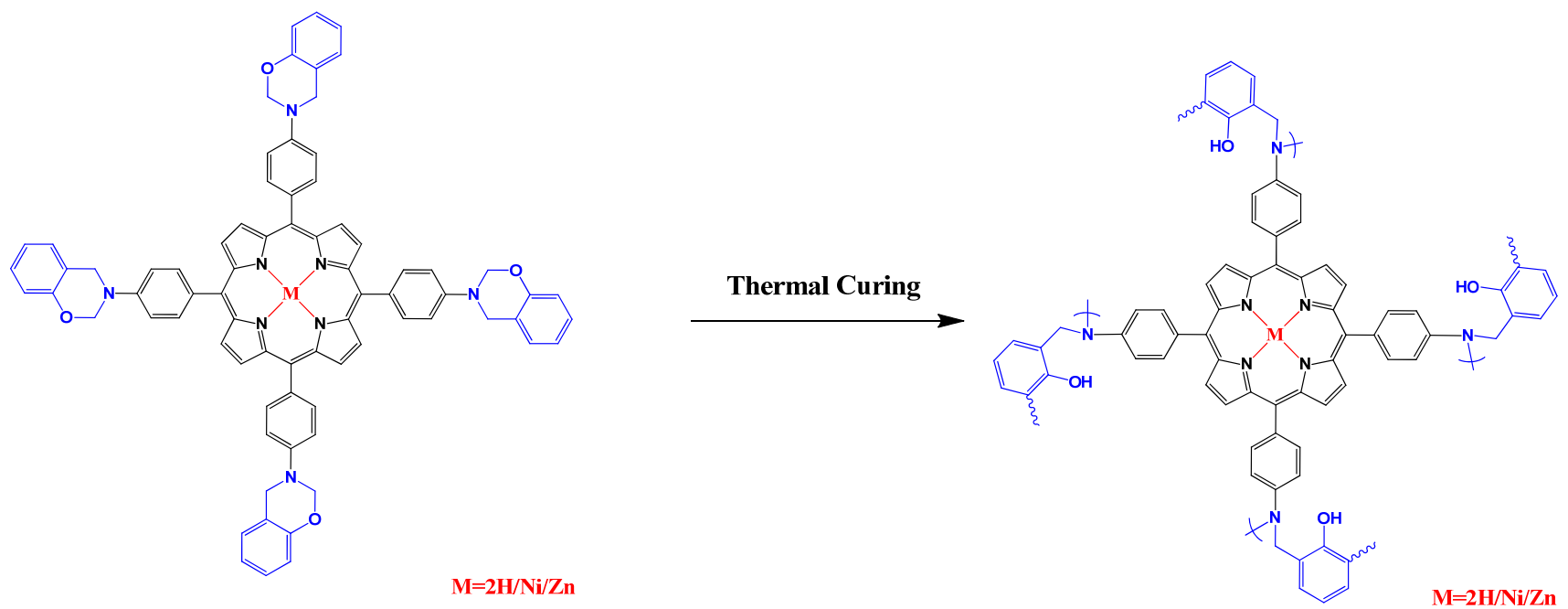

Scheme 3. Thermal ring-opening polymerization of the Por-BZ, Por-BZ/Ni, and Por-BZ/Zn.

\section{Results and Discussion}

\subsection{Synthesis of TAPP}

Scheme 1 presents the synthesis of the monomer Por-BZ from 4-nitrobenzaldehyde (Scheme 1a). First, we prepared TNPP (Scheme 1b) through the reaction of 4-nitrobenzaldehyde with pyrrole in the presence of propionic acid and acetic anhydride at $130^{\circ} \mathrm{C}$. The reduction of TNPP with $\mathrm{HCl}$ and $\mathrm{SnCl}_{2} \cdot \mathrm{H}_{2} \mathrm{O}$ at $70{ }^{\circ} \mathrm{C}$ for $2 \mathrm{~h}$ provided TAPP as violet microcrystals in high yield and purity (Scheme 1c); FTIR and NMR spectroscopy confirmed the chemical structure. Figure 1a-c display the FTIR spectra of 4-nitrobenzaldehyde, TNPP, and TAPP, respectively, each recorded at room temperature. The signals for the $\mathrm{NO}_{2}$ units appeared near 1346 and $1593 \mathrm{~cm}^{-1}$ for both 4-nitrobenzaldehyde and TNPP; the signals of the $\mathrm{CHO}$ unit of 4-nitrobenzaldehyde at 2855, 2776, $2733(\mathrm{C}-\mathrm{H})$ and $1700(\mathrm{C}=\mathrm{O}) \mathrm{cm}^{-1}$ were 
absent from the spectrum of TNPP, but signals appeared for an NH unit at $3312 \mathrm{~cm}^{-1}$ and a $\mathrm{C}=\mathrm{N}$ unit at $1596 \mathrm{~cm}^{-1}$ [51]. In the spectrum of TAPP, the signals of the $\mathrm{NO}_{2}$ units had almost disappeared, with two new absorption peaks appearing for $\mathrm{NH}_{2}$ units at 3352 and $3439 \mathrm{~cm}^{-1}$. Figure 2 show ${ }^{1} \mathrm{H}$ and ${ }^{13} \mathrm{C}$ NMR spectra of TAPP. The signals of the $\mathrm{NH}$ and $\mathrm{NH}_{2}$ protons appeared at 3.57 and $5.56 \mathrm{ppm}$, respectively (Figure 2A). The signal at $149.32 \mathrm{ppm}$ in Figure 2B represents to the $\mathrm{C}-\mathrm{N}$ units of TAPP, confirming the successful reduction of TNPP to form TAPP in high purity.
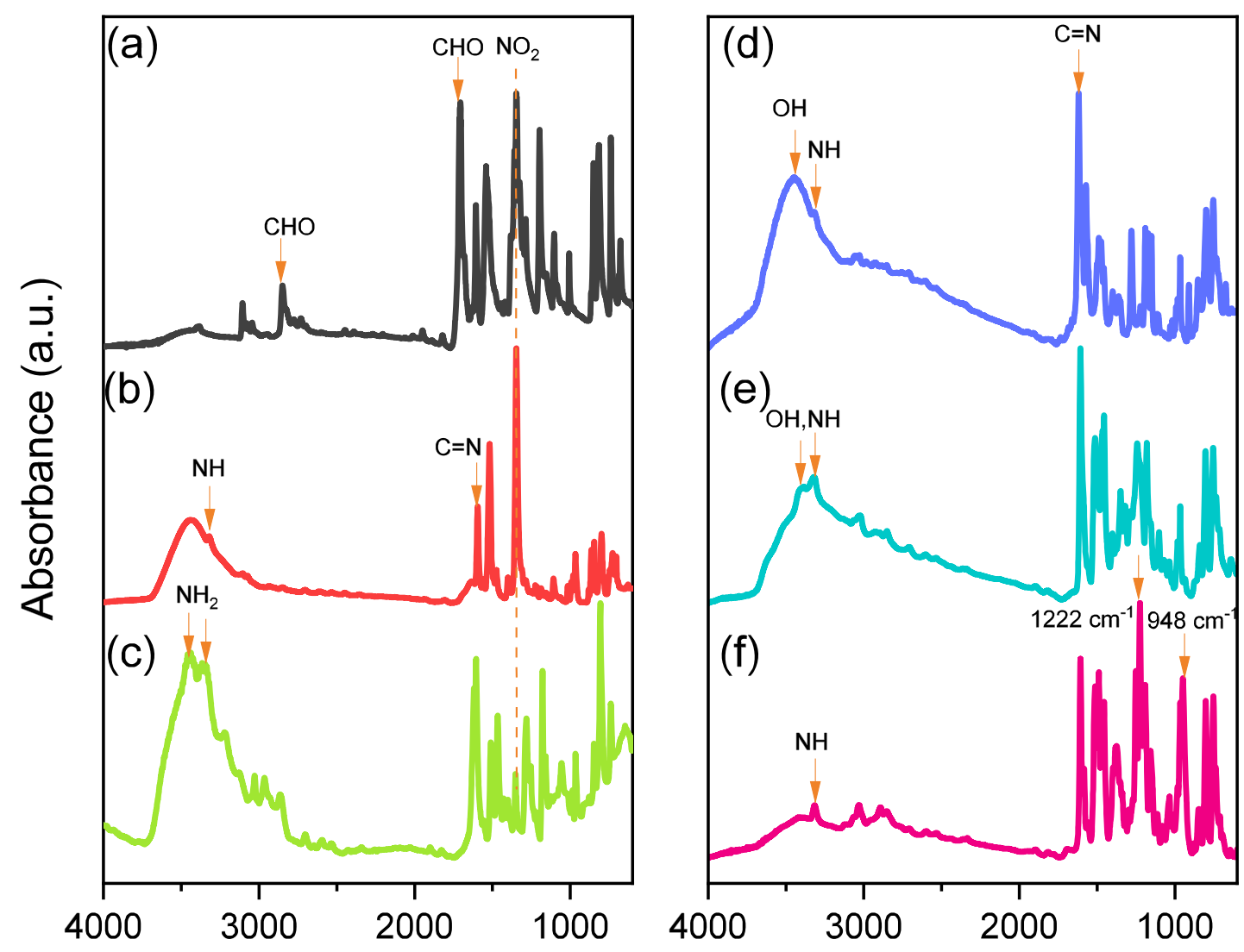

Figure 1. FTIR spectra of (a) 4-nitrobenzaldehyde, (b) TNPP, (c) TAPP, (d) Por-Sa, (e) Por-Hy, and (f) Por-BZ.

\subsection{Synthesis of Por-BZ}

Although TAPP features four amino groups, one-pot Mannich condensations from primary amines, phenol, and $\mathrm{CH}_{2} \mathrm{O}$ do not always occur in the preparation of $\mathrm{BZ}$ monomers due to low selectivity, which is strongly dependent on the substituent positions. In previous studies [27], we used the approach described by Ishida and Lin et al. to prepare BZ rings through a three-step synthesis (Scheme 1d-f). Here, we used the Schiff base formed from TAPP and salicylaldehyde to first form porphyrin-salicylaldehyde (Por-Sa) (Scheme 1d). Next, we reduced Por-Sa to form the $o$-hydroxybenzylamine derivative Por-Hy (Scheme 1e). Finally, the reaction of Por-Hy with the aldehyde derivative was provided the target monomer Por-BZ (Scheme 1f).

Figure 1 also presents FTIR spectra of Por-Sa, Por-Hy, and the monomer Por-BZ, recorded at room temperature. The $\mathrm{O}-\mathrm{H}$ and $\mathrm{N}-\mathrm{H}$ stretching absorptions appeared near 3455 and $3409 \mathrm{~cm}^{-1}$ for Por-Sa (Figure 1d) and Por-Hy (Figure 1e), respectively. After the reaction with paraformaldehyde, the signal of the $\mathrm{OH}$ groups was absent from the spectrum of the Por-BZ monomer, with the main characteristic signals being those for the oxazine ring $\left(948 \mathrm{~cm}^{-1}\right), \mathrm{C}-\mathrm{O}$ stretching $\left(1222 \mathrm{~cm}^{-1}\right)$, and $\mathrm{N}-\mathrm{H}$ stretching of the pyrrole units $\left(3319 \mathrm{~cm}^{-1}\right)$, indicative of the BZ ring having formed. Figure 2 displays ${ }^{1} \mathrm{H}$ and ${ }^{13} \mathrm{C}$ NMR spectra of Por-Sa (Figure 2b), Por-Hy (Figure 2c), and Por-BZ monomer (Figure 2d) 
in DMSO- $d_{6}$. The signals of the $\mathrm{NH}_{2}$ units of TAPP were absent in the spectrum of Por-Sa (Figure 2A-b), with characteristic signals appearing for the $\mathrm{N}=\mathrm{CH}, \mathrm{OH}$, and $\mathrm{NH}$ units at $10.24,10.72$, and $8.90 \mathrm{ppm}$, respectively, along with signals for aromatic protons in the range 8.30-6.87 ppm. The spectrum of Por-Hy (Figure 2A-c) also featured signals for aromatic protons (7.88-6.87 ppm), but the signal of the $\mathrm{N}=\mathrm{CH}$ units of Por-Sa (at $10.24 \mathrm{ppm}$ ) was disappeared, with the new signal for $\mathrm{NHCH}_{2}$ units appearing at $4.45 \mathrm{ppm}$, in addition to signals for the $\mathrm{NH}$ and $\mathrm{OH}$ units at 9.62 and $8.85 \mathrm{ppm}$, respectively. The high-field signal of the $\mathrm{OH}$ units was due to a change in intramolecular hydrogen bonding after the reduction of Por-Sa. The spectrum of Por-BZ (Figure 2A-d) featured signals for aromatic rings and $\mathrm{NH}$ units at $8.06-6.85$ and $8.78 \mathrm{ppm}$, respectively. Furthermore, the signals of the oxazine ring protons were appeared at $4.93\left(\mathrm{ArCH}_{2} \mathrm{~N}\right)$ and $5.72\left(\mathrm{OCH}_{2} \mathrm{~N}\right)$ ppm with equal integral intensity. The corresponding ${ }^{13} \mathrm{C}$ NMR spectra confirmed their chemical structures (Figure 2B). The ${ }^{13} \mathrm{C}$ NMR spectrum of Por-Sa (Figure 2B-b) featured signals at $192.67,161.75$, and 137.02-117.54 ppm for the $\mathrm{N}=\mathrm{CH}, \mathrm{COH}$, and aromatic carbon nuclei, respectively. The Por-Hy spectrum featured a new peak at $41.56 \mathrm{ppm}$ for the $\mathrm{NHCH}_{2}$ carbon nuclei (Figure 2B-c). The characteristic signals for Por-BZ appeared at $49.16\left(\mathrm{ArCH}_{2} \mathrm{~N}\right)$ and $78.80\left(\mathrm{OCH}_{2} \mathrm{~N}\right) \mathrm{ppm}$, indicating that the $\mathrm{BZ}$ ring had been synthesized with high purity and yield.

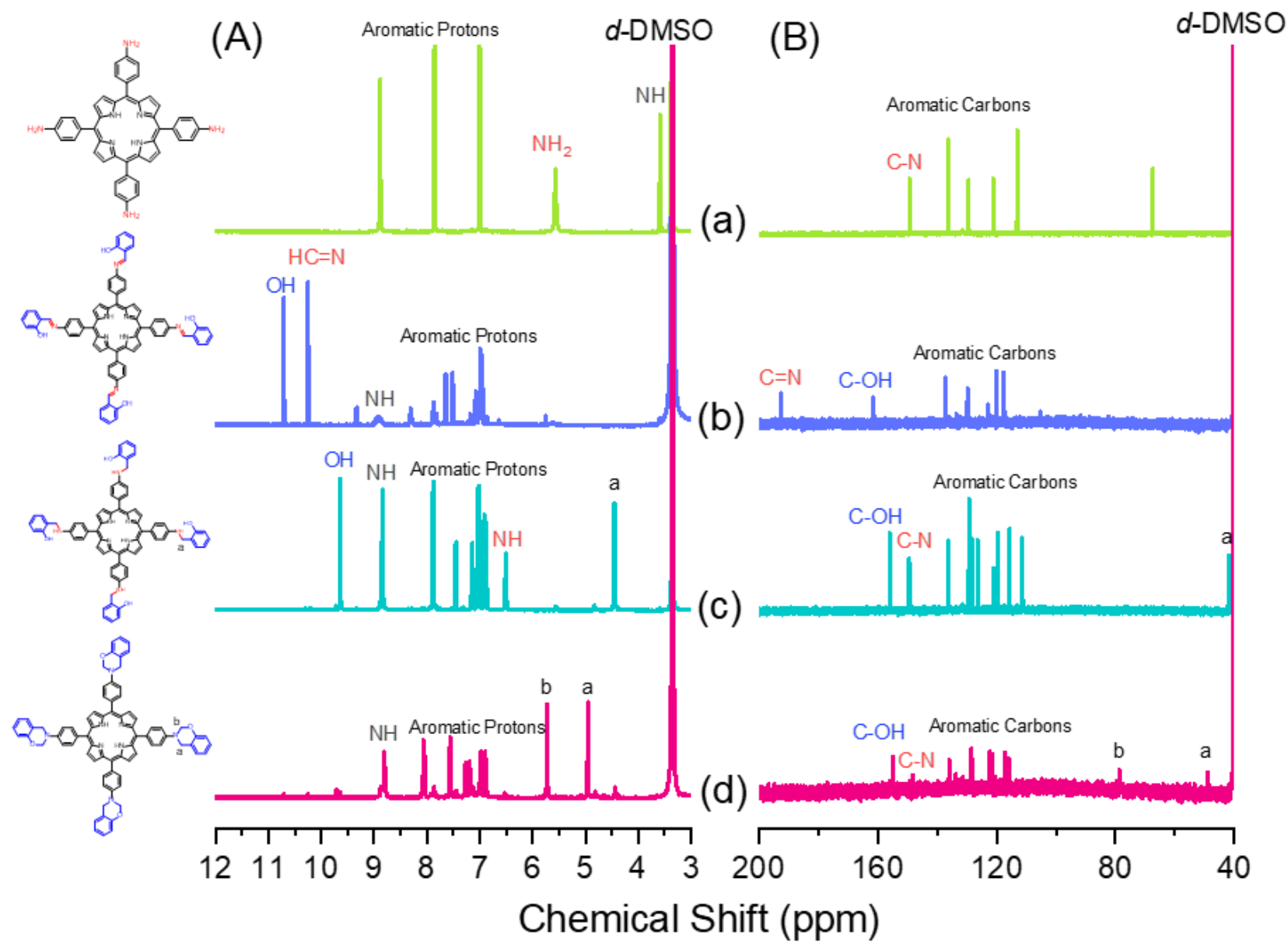

Figure 2. (A) ${ }^{1} \mathrm{H}$ and (B) ${ }^{13} \mathrm{C}$ NMR spectra of (a) TAPP, (b) Por-Sa, (c) Por-Hy, and (d) Por-BZ.

\subsection{Thermal Curing Polymerization of Por-BZ Monomer}

We used DSC, TGA, and FTIR spectroscopy to investigate the thermal curing polymerization of the Por-BZ monomer. Figure 3A displays DSC traces of pure Por-BZ monomer, which provided a high exothermic maximum curing temperature of $314{ }^{\circ} \mathrm{C}$ and the reaction heat of $163 \mathrm{~J} \mathrm{~g}^{-1}$. Compared with the typical thermal curing temperature of a Pa-type BZ 
monomer $\left(255-263^{\circ} \mathrm{C}\right)$, the significantly higher value for pure Por-BZ monomer was presumably because the rigid structure of its porphyrin unit inhibited ROP at relatively high temperatures. After thermal polymerizations at 150,180 , and $210^{\circ} \mathrm{C}$, the polymerization temperatures of Por-BZ shifted to 312,312 , and $295^{\circ} \mathrm{C}$, respectively, with the reaction heat of 144,138 , and $80 \mathrm{~J} \mathrm{~g}^{-1}$, respectively. In addition, after thermal curing polymerization at $240{ }^{\circ} \mathrm{C}$ for $2 \mathrm{~h}$, no obvious exothermic peak was observed, suggesting that the complete ROP of the Por-BZ monomer had occurred at this temperature to form poly(Por-BZ). Figure $3 \mathrm{~B}$ displays the FTIR spectra of Por-BZ after its thermal polymerizations at the various temperatures. The signals of $\mathrm{BZ}$ units at 1222 and $948 \mathrm{~cm}^{-1}$ decreased gradually upon increasing the thermal polymerization temperature, consistent with ring-opening of the oxazine structure. After the temperature had increased to $240{ }^{\circ} \mathrm{C}$, the signals of the oxazine ring disappeared completely based on the FTIR spectra, suggesting the formation of the highly cross-linked poly(Por-BZ) structure (Scheme S1), which is consistent with DSC data.

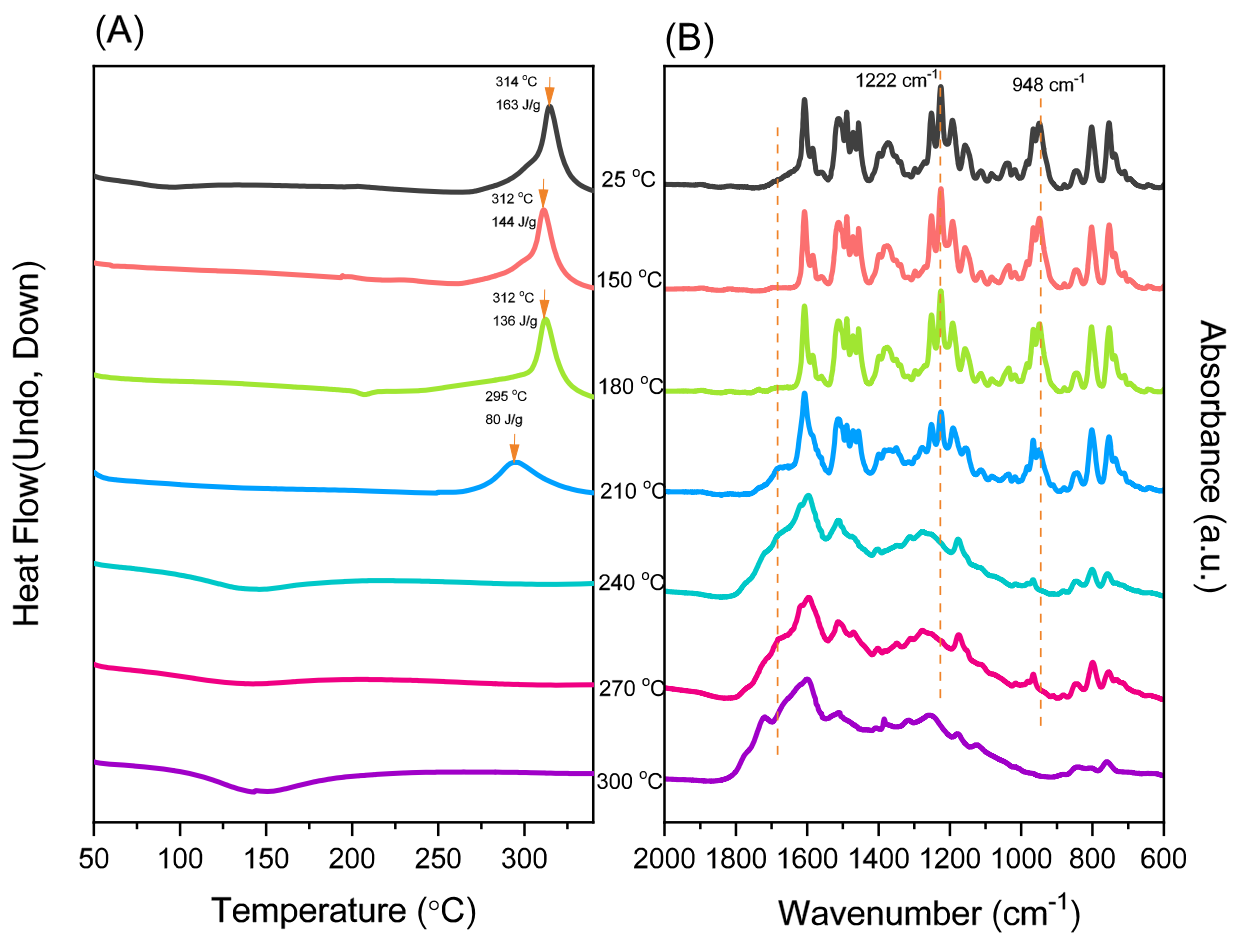

Figure 3. (A) DSC and (B) FTIR spectral analyses of the Por-BZ monomer after thermal ROP at various temperatures.

Furthermore, we used TGA to investigate the thermal properties of Por-BZ monomer after thermal ROP at different temperatures. Figure $4 \mathrm{~A}$ shows that the thermal decomposition temperatures $\left(T_{\mathrm{d} 10}\right)$ for the Por-BZ monomer thermally cured at 25, 180, 210, 240, 270, and $300{ }^{\circ} \mathrm{C}$ were $434,445,453,454,460$, and $478{ }^{\circ} \mathrm{C}$, respectively; the corresponding char yields were $55,57,61,62,63$, and $66 \mathrm{wt} \%$, respectively. The $T_{\mathrm{d} 10}$ values and char yields of this new poly(Por-BZ) were higher than those of traditional BZs (typically $405^{\circ} \mathrm{C}$ and $35 \mathrm{wt} \%$, respectively), presumably because of the presence of highly aromatic structures. The $T_{\mathrm{d}}$ and char yield were both increased with the increase in thermal ROP temperature, suggesting structures of higher cross-linking density. Figure $4 \mathrm{~B}$ reveals that the exothermic peaks of Por-BZ near $300{ }^{\circ} \mathrm{C}$ disappeared gradually with the increase in the thermal polymerization temperature, and were completely absent after thermal treatment at $240{ }^{\circ} \mathrm{C}$, consistent with the DSC and FTIR results in Figure 3. 
(A)

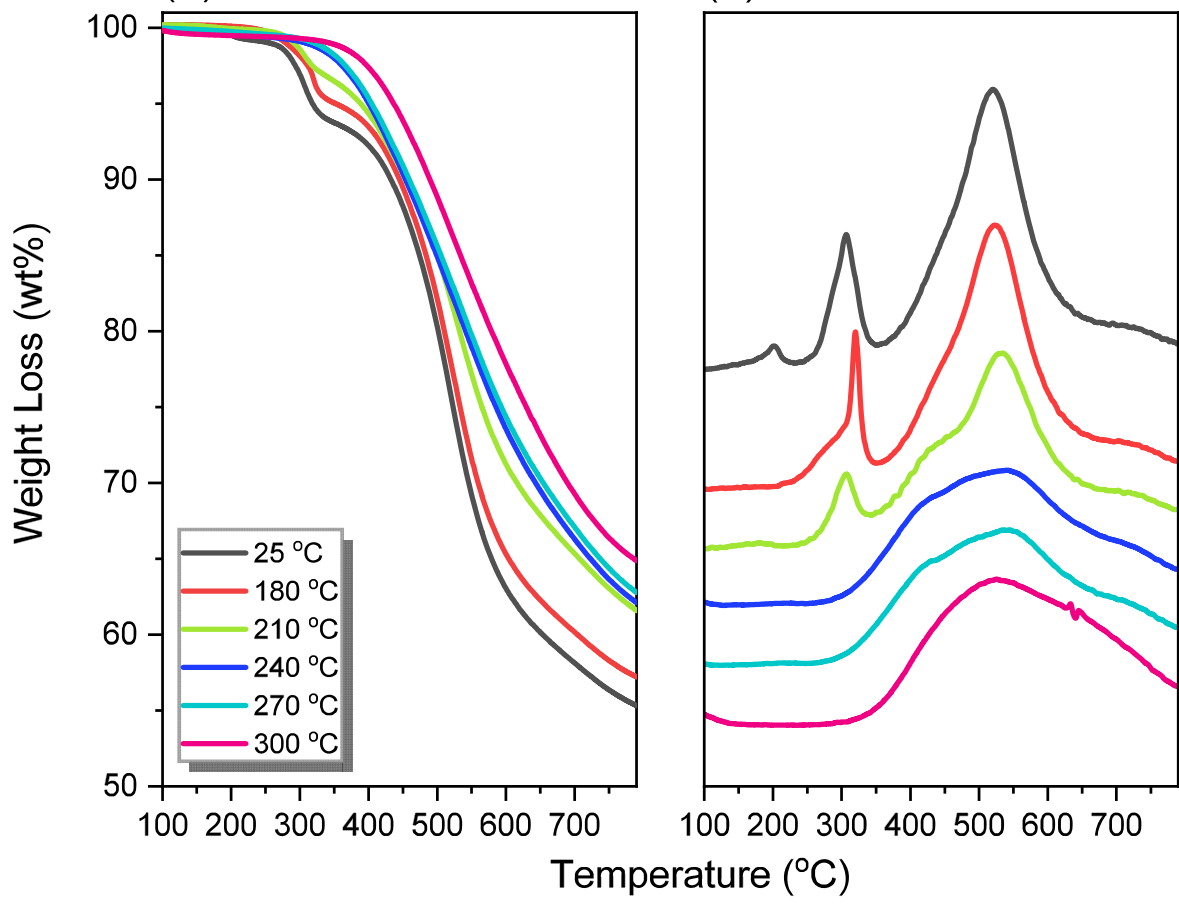

(B)

Figure 4. (A) TGA and (B) corresponding second-derivative curves based on TGA analyses of the Por-BZ monomer after thermal ROP at various temperatures.

\subsection{Characterization of Por-BZ/Metal Complex}

Because porphyrins are excellent moieties for complexing metal cations, we tested the ability of our Por-BZ to bind $\mathrm{Ni}^{2+}$ and $\mathrm{Zn}^{2+}$ ions [52,53]. We used DSC and FTIR spectroscopy to demonstrate the incorporation of these metal ions into the porphyrin structures, and DSC thermograms to record the thermal ROP behavior of the Por-BZ/Ni and Por-BZ/Zn complexes. Figure 5A presents that the thermal curing peaks of the uncured Por$\mathrm{BZ} / \mathrm{Ni}$ and Por-BZ/Zn complexes were centered at 241 and $231^{\circ} \mathrm{C}$, respectively, implying that the metal ions could act as catalysts for the ROPs of the BZ rings. In previous studies we found that the mechanism through which these metal ions catalyze the ring-opening of BZ involves three steps: first, the metal ion coordinates the nitrogen or oxygen atom in the oxazine ring structure, and then the next electrophilic attack of the metal ions to the oxazine ring occurs. Finally, the rearrangement was occurred to form the stable phenolic and phenoxy structures [3]. Figure 5B presents FTIR spectra of Por-BZ and the Por-BZ/Ni and Por-BZ/Zn complexes, measured at room temperature. The BZ structure (signals at 1222 and $948 \mathrm{~cm}^{-1}$ ) remained for the uncured Por-BZ/Ni and Por-BZ/Zn complexes. Meanwhile, the signal at $3316 \mathrm{~cm}^{-1}$ for NH stretching of the pyrrole ring had disappeared, suggesting that the metal ions had been inserted into the porphyrin structure, replacing the original pyrrole protons (Scheme 2b), with new signals observed at 1663 and $991 \mathrm{~cm}^{-1}$ in the FTIR spectra of the Por-BZ/Ni and Por-BZ/Zn complexes, arising from coordination of the metal ions with the porphyrin structures.

The incorporation of $\mathrm{Ni}^{2+}$ and $\mathrm{Zn}^{2+}$ ions into the porphyrin structures was futher confirmed using X-ray photoelectron spectroscopy (XPS). As observed in Figure 6, the Por-BZ exhibited three peaks at 285.27, 398.58, and $533.56 \mathrm{eV}$ for the carbon, nitrogen, and oxgyen atoms, respectively. The Por-BZ/Ni complex featured four charatersitic peaks at 285.27, 399.95, 534.70, 858.45 eV for the carbon, nitrogen, oxgyen, and nickel atoms, respectively, while the Por-BZ/Zn complex exhibited four peaks at 285.28, 399.94, 533.96, and $1021.02 \mathrm{eV}$ for carbon, nitrogen, oxgyen, and zinc atoms, respectively. The apperance of nickel and zinc peaks confirmed the successful incorporation of metal ions in the porphyrin units. To have a better understanding of the different types of $\mathrm{N}$ and metal species found 
in Por-BZ, and the Por-BZ/Ni and Por-BZ/Zn complexes, we fitted their XPS peaks for the $\mathrm{N}$ 1s, Ni 2p, and Zn 2p orbitals (Figure 7). Figure 7a revealed that the free-base porphyrin Por-Bz had two different types of $\mathrm{N}$ 1s species: iminic nitrogen $(=\mathrm{N}-)$ at $398.50 \mathrm{eV}$ and aminic nitrogen (-NH-) at $399.53 \mathrm{eV}$. The area fractions of iminic and aminic nitrogen were found to be 57 and $43 \%$, respectively. On the other hand, Por-BZ/Ni and Por-BZ/Zn complexes possessed two types of $\mathrm{N}$ 1s species at 398.88 and $398.87 \mathrm{eV}$ for iminic nitrogens, respectively, and at 399.77 and $399.98 \mathrm{eV}$ for aminic nitrogens, respectively (Figure 7b,c). The area fractions of iminic and aminic nitrogen were found to be 86 and $14 \%$, respectively, and for the Por-BZ/Ni complexe, 87 and 13\%, respectively. The strong decreasing of the peaks of aminic nitrogens in Por-BZ/Ni and Por-BZ/Zn complexes confirmed the metal ions had been incorporated into the porphyrin structure, taking the place of the original pyrrole protons. Futhermore, the Por-BZ did not show the metal ion peaks (Figure 7d), while the fitting of XPS peaks for the Ni $2 p$, and $\mathrm{Zn} 2 \mathrm{p}$ orbitals revealed that the Por-BZ/Ni complex had four Ni $2 \mathrm{p}$ species: $\mathrm{Ni} 2 \mathrm{p}_{3 / 2}(857.88 \mathrm{eV}), \mathrm{Ni} 2 \mathrm{p}_{3 / 2}$ satellite $(865.43 \mathrm{eV}), \mathrm{Ni}$ $2 \mathrm{p}_{1 / 2}(874.79 \mathrm{eV})$, and Ni $2 \mathrm{p}_{1 / 2}$ satellite $(882.25 \mathrm{eV})$ (Figure $\left.7 \mathrm{e}\right)$. The Por-BZ/Zn complex had two Zn 2p species: Zn 2 $p_{3 / 2}(1022.91 \mathrm{eV})$ and Zn 2p $1 / 2$ (1045.75 eV) (Figure 7f).
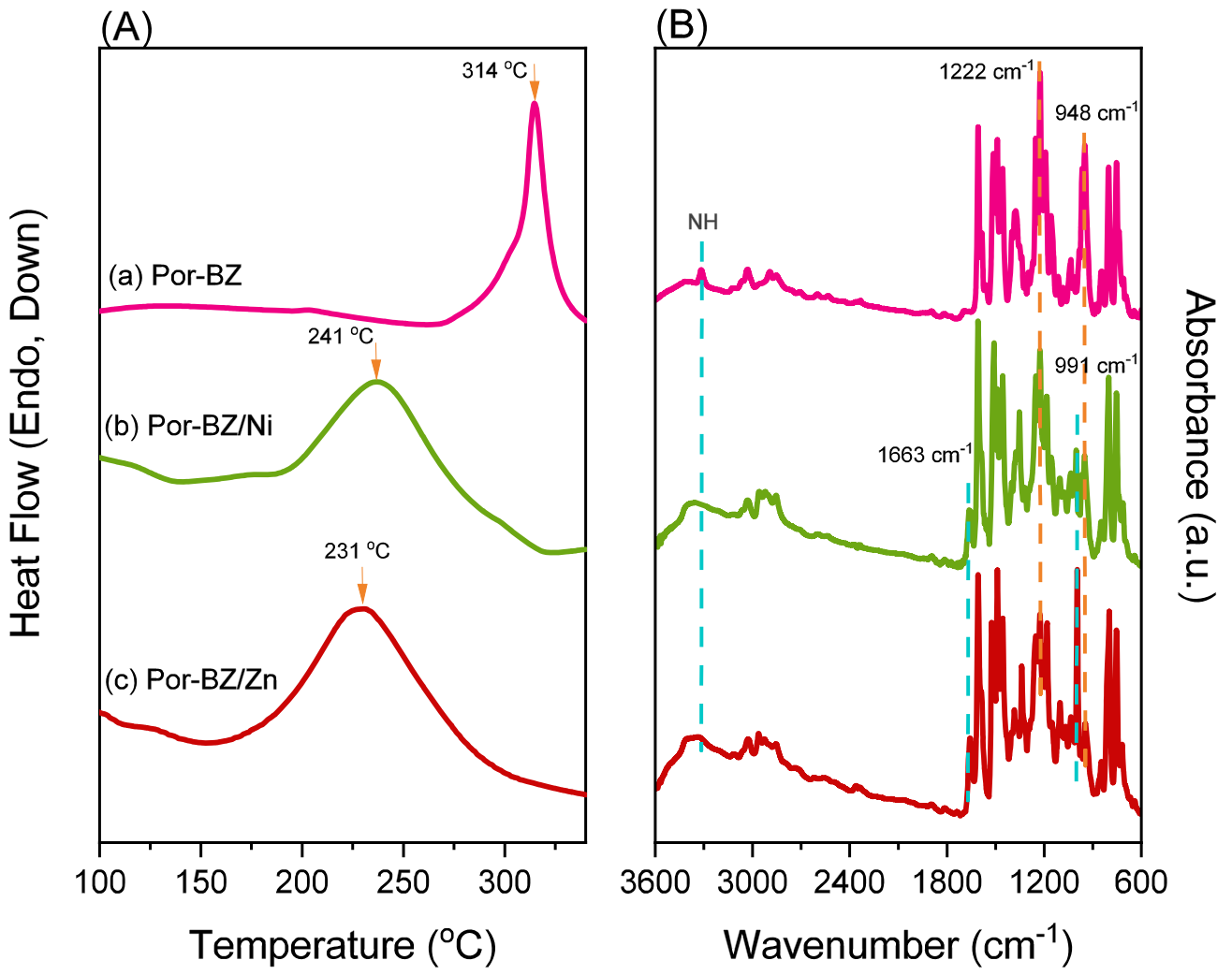

Figure 5. (A) DSC and (B) FTIR spectral analyses of the (a) Por-BZ monomer, (b) Por-BZ/Ni complex, and (c) Por-BZ/Zn complex prior to thermal ROP. 


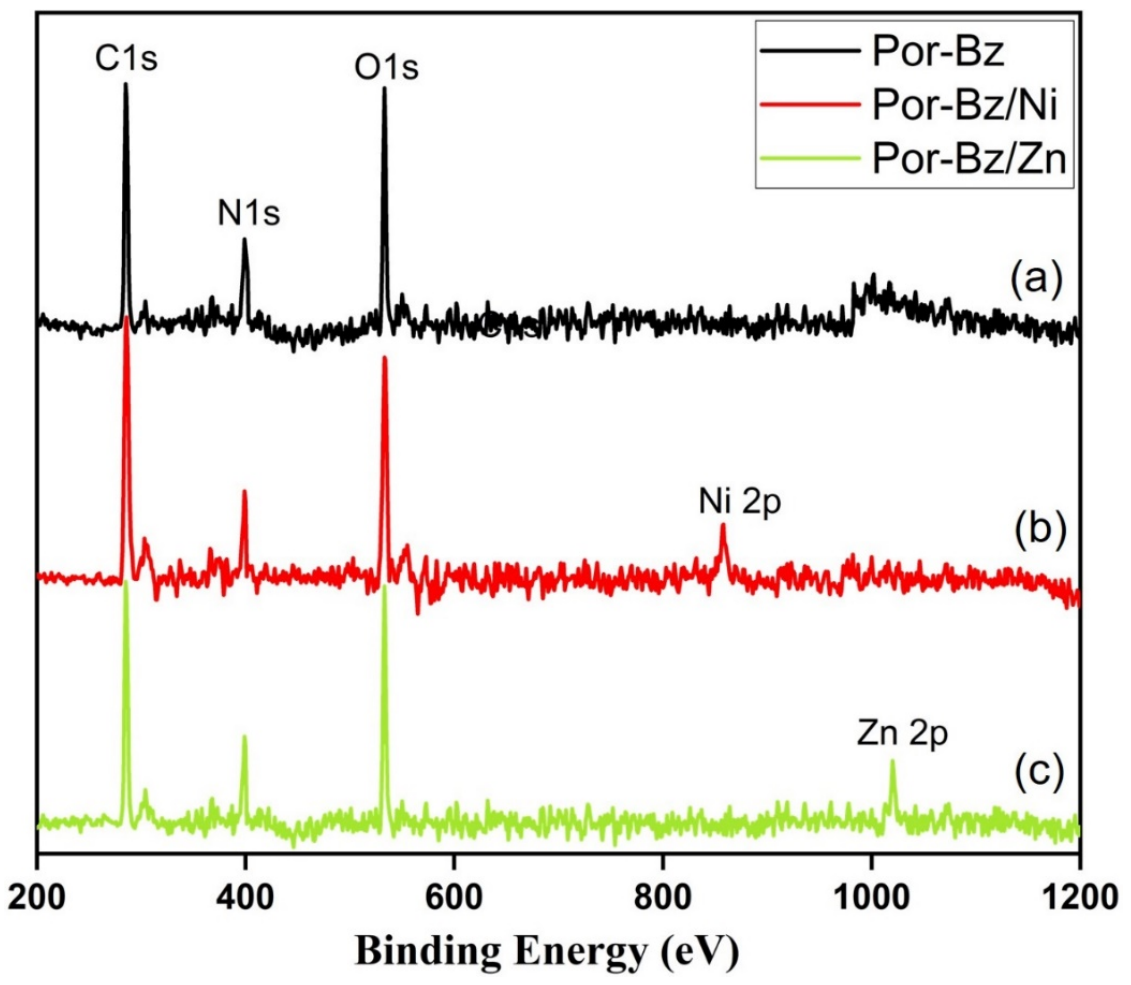

Figure 6. XPS spectra of the (a) Por-BZ monomer, (b) Por-BZ/Ni complex, and (c) Por-BZ/Zn complex.
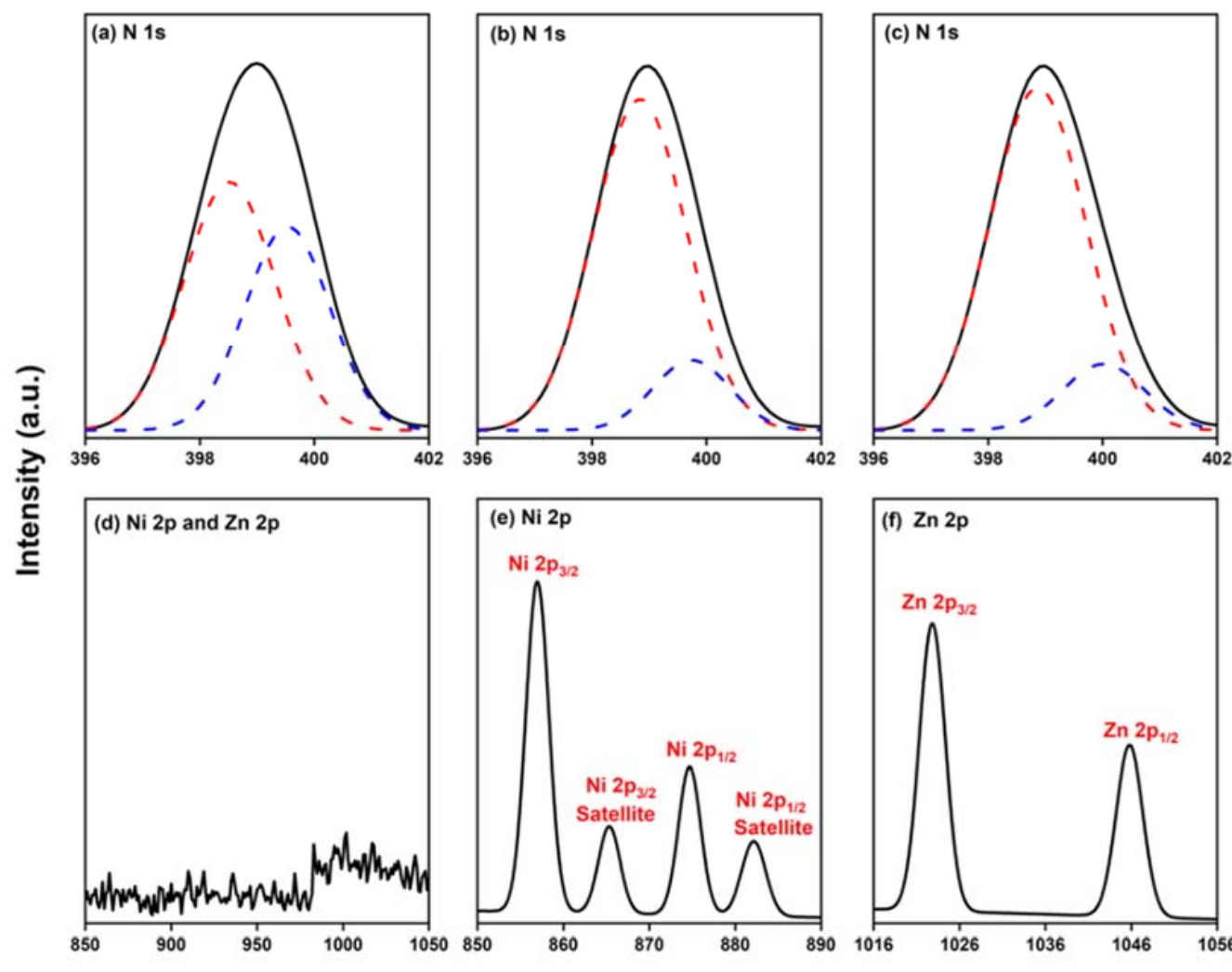

Binding Energy (eV)

Figure 7. XPS spectra of the N1s species (a) Por-BZ monomer, (b) Por-BZ/Ni complex, and (c) Por-BZ/Zn complex. XPS spectra of (d) the Ni 2p, and Zn 2p species of Por-BZ monomer, (e) the Ni $2 p$ species of Por-BZ/Ni complex, and (f) the Zn 2p species of Por-BZ/Zn complex. 
To study the luminescence properties of TAPP, Por-BZ, and the Por-BZ/Ni and Por$\mathrm{BZ} / \mathrm{Zn}$ complexes in various solvents, we recorded their UV-Vis absorption spectra at room temperature (Figure 8 , Table 1 ). The highly conjugated porphyrin structure usually exhibits the following features in its UV-Vis absorption spectrum: a very strong absorption band near $400 \mathrm{~nm}$, named the Soret band, resulting from the transition of electrons from the $\mathrm{S}_{0}$ to $\mathrm{S}_{2}$ state; and several weaker signals between 450 and $700 \mathrm{~nm}$, corresponding to the $Q$ band and representing electronic transitions from $S_{0}$ to $S_{1}$ [54]. The main peaks of soret bands and $Q$ bands of our products were shown in Table 1. Placing exterior substituents on the porphyrin ring usually induces minor changes in the wavelengths and intensities of the absorption bands, while protonation of the two inner nitrogen atoms or the insertion (or change) of a metal atom at the core of the porphyrin generally has a dramatic effect on the visible absorption spectrum [54]. Compared with the absorption bands of TAPP (Figure 8a), the absorption bands of Por-BZ (Figure $8 \mathrm{~b}$ ) were slightly blue-shifted within $8 \mathrm{~nm}$, whereas the addition of the metal ions caused the bands to red-shift dramatically. After metalation, the peaks of Soret bands red-shifted about $15 \mathrm{~nm}$ from Por-BZ to Por-BZ/Ni, and about $40 \mathrm{~nm}$ for Por-BZ/Zn; meanwhile $\mathrm{Q}$ bands red-shifted about $6 \mathrm{~nm}$ after adding $\mathrm{Ni}^{2+}$ ions and $12 \mathrm{~nm}$ for $\mathrm{Zi}^{2+}$, relatively. We suspect that the electron-donating units on the phenyl groups at the meso positions of the porphyrin ring enhanced the electron density of the phenyl ring, causing the phenyl ring to conjugate with the porphyrin macrocycle to a certain degree. This kind of conjugation would likely lower the electron transition energy of the porphyrin macrocycle, resulting in red-shifts of the absorption bands. After transforming the $\mathrm{NH}_{2}$ units to $\mathrm{BZ}$ rings, this interaction was inhibited, causing the adsorption bands to be blue-shifted. After bonding to the central nitrogen atoms of a porphyrin, metal ions accept the lone pairs of electrons of the $\mathrm{N}$ atoms of the pyrrole rings, with the metal ions donating electrons to the porphyrin ring to induce delocalized $\pi$-bonds, which permit the ready flow of electrons within the delocalized $\pi$-system. In this study, after adding metal ions (Figure $8 \mathrm{c}, \mathrm{d}$ ), the number of $\mathrm{Q}$ bands decreased and their absorption frequencies shifted. When the metal ions coordinated with porphyrin ligand, the symmetry of the molecule changed from $\mathrm{D}_{2 \mathrm{~h}}$ to $\mathrm{D}_{4 \mathrm{~h}}$, with the cleavage degree of the molecular orbital decreasing and the degeneracy increasing; hence, the number of $\mathrm{Q}$ bands decreased $[55,56]$.

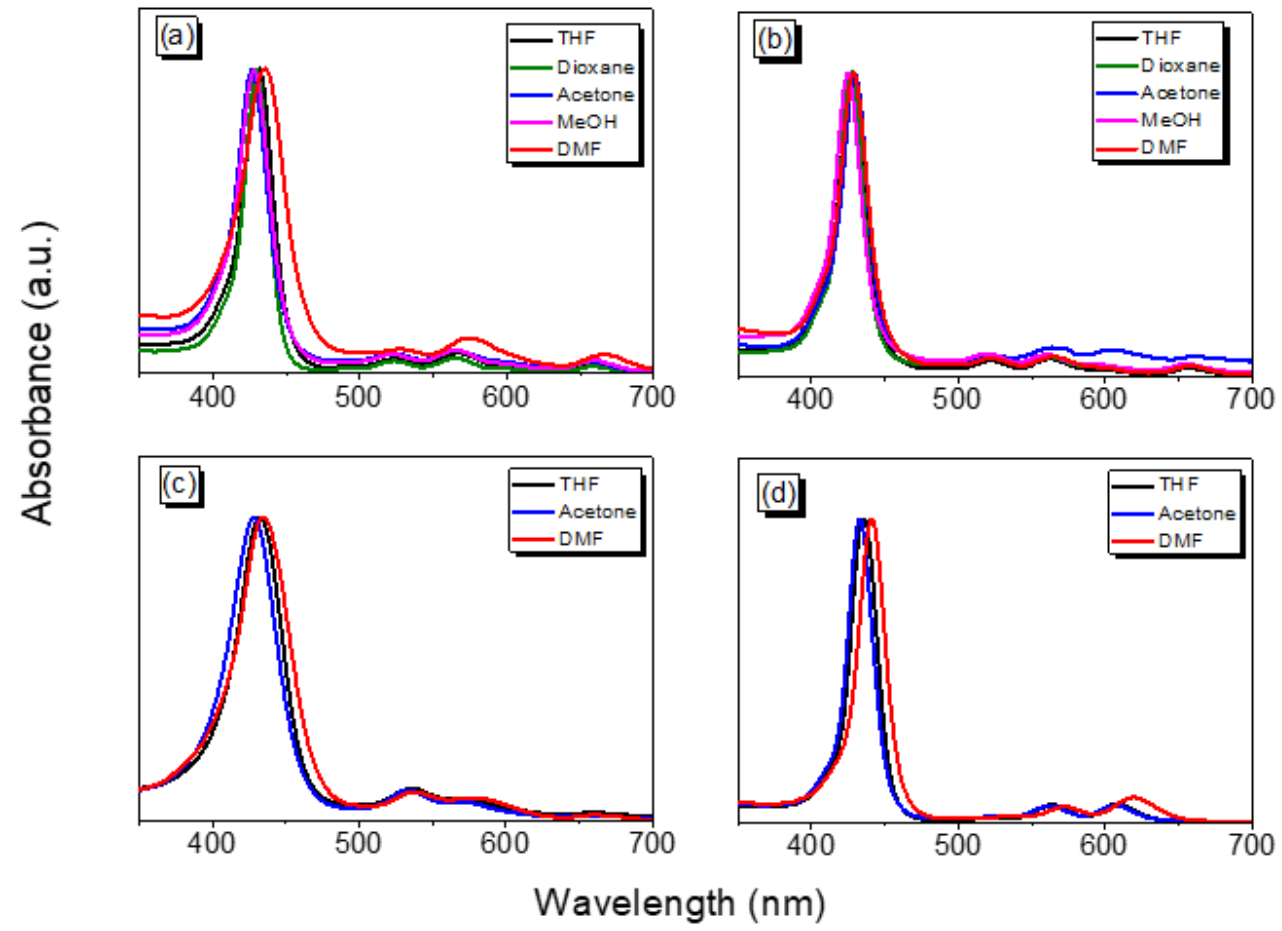

Figure 8. UV-Vis absorption spectra of (a) TAPP, (b) Por-BZ, (c) the Por-BZ/Ni complex, and (d) the Por-BZ/Zn complex. 
Table 1. The main peaks in the UV/Vis spectra of TAPP, Por-BZ, Por-BZ/Ni and Por-BZ/Zn.

\begin{tabular}{cccc}
\hline Compound & Solvent & $\boldsymbol{\lambda}_{\text {abs }}(\mathbf{n m}) \mathbf{( S o r e t}$ Band) & $\boldsymbol{\lambda}_{\text {abs }}$ (nm) (Q Band) \\
\hline & THF & $524,566,602,662$ & 432 \\
TAPP & Dioxane & $524,564,600,660$ & 430 \\
& Acetone & $522,564,600,660$ & 428 \\
& MeOH & $522,564,596,656$ & 436 \\
DMF & $528,574,608,666$ & 428 \\
Por-BZ & THF & $522,562,598,658$ & 428 \\
& Dioxane & $522,562,598,656$ & 424 \\
& Acetone & $520,560,596,654$ & 430 \\
& MeOH & $522,564,606,662$ & 428 \\
\hline & DMF & $522,564,600,658$ & 432 \\
Por-BZ/Ni & THF & $535,574,657.5$ & 428 \\
& Acetone & $533.5,571,656.5$ & 434 \\
\hline & DMF & $538,579,660.5$ & 436 \\
\hline & THF & 564,608 & 432 \\
\hline
\end{tabular}

We also recorded PL spectra to measure the fluorescence properties of TAPP, Por$\mathrm{BZ}$, and the Por-BZ/Ni and Por-BZ/Zn complexes dissolved in several kinds of solvents (Figure 9). Fluorescent materials with highly $\pi$-conjugated systems typically exhibit strong luminescence in dilute solution; their fluorescence emissions are typical quenched in solutions of high concentrations or in the solid state, a phenomenon known as "aggregationcaused quenching" (ACQ), a result of strong face-to-face $\pi$-stacking [57-61]. Therefore, we investigated the effect of concentration on the fluorescence emissions of TAPP and Por-BZ in DMF upon excitation at a wavelength of $360 \mathrm{~nm}$. Figure $\mathrm{S} 1$ reveals that the emission intensity decreased upon increasing the concentrations of both TAPP and Por-BZ in DMF, confirming their ACQ behavior. Furthermore, we investigated the PL behavior of TAPP, Por-BZ, and the Por-BZ/Ni and Por-BZ/Zn complexes by recording their fluorescence emissions when dispersed in various solvents. In general, we prepared solutions of our powder products dissolved in the various solvents at a concentration of $10^{-4} \mathrm{~mol} \mathrm{~L}^{-1}$. It was relatively difficult to dissolve Por-BZ and the Por-BZ/Zn complex in $\mathrm{MeOH}$; PorphyrinBZ-Ni formed suspensions in these organic solvents. The emission spectra are presented in Figure 7, after excitation at a wavelength of $360 \mathrm{~nm}$. According to previous reports [55,62], the typical emission spectrum for a porphyrin shows two peaks centered at approximately 650 and $720 \mathrm{~nm}$, due to the $\mathrm{Q}(0-0)$ and the $\mathrm{Q}(0-1)$ transitions, respectively. Excitation of our porphyrin derivatives to the $\mathrm{S} 2$ ( $\mathrm{B}$ band) and $\mathrm{S} 1$ ( $\mathrm{Q}$ band) levels resulted in fluorescence, with the fluorescence of the $\mathrm{S} 2$ ( $\mathrm{B}$ band) - representing the transition from the second excited singlet state $\mathrm{S} 2$ to the ground state $\mathrm{S} 0$ ( $\mathrm{S} 2 \rightarrow \mathrm{S} 0$ ) — corresponding to the Soret band in the UVVis absorption spectra. The fluorescence of the $\mathrm{Q}$ band is corresponding to the transition from the lowest excited singlet state $\mathrm{S} 1$ to the ground state $\mathrm{S} 0$. The fluorescence of $\mathrm{S} 2 \rightarrow \mathrm{S} 0$ was too weak to be observed in this study, owing to the light scattering and resorption of the strong Soret absorption bands. Interestingly, compared with the fluorescent bands of TAPP and Por-BZ, the emission peaks of the Por-BZ/Zn complex were much stronger and had been blue-shifted significantly, from $665 \mathrm{~nm}$ to $630 \mathrm{~nm}$. Nevertheless, the PL intensity of the Por-BZ/Ni complex was lower than that of Por-BZ, with no shifts of the peaks. Thus, the addition of different kinds of metal ions had dramatically different impacts on the fluorescence properties of Por-BZ. 


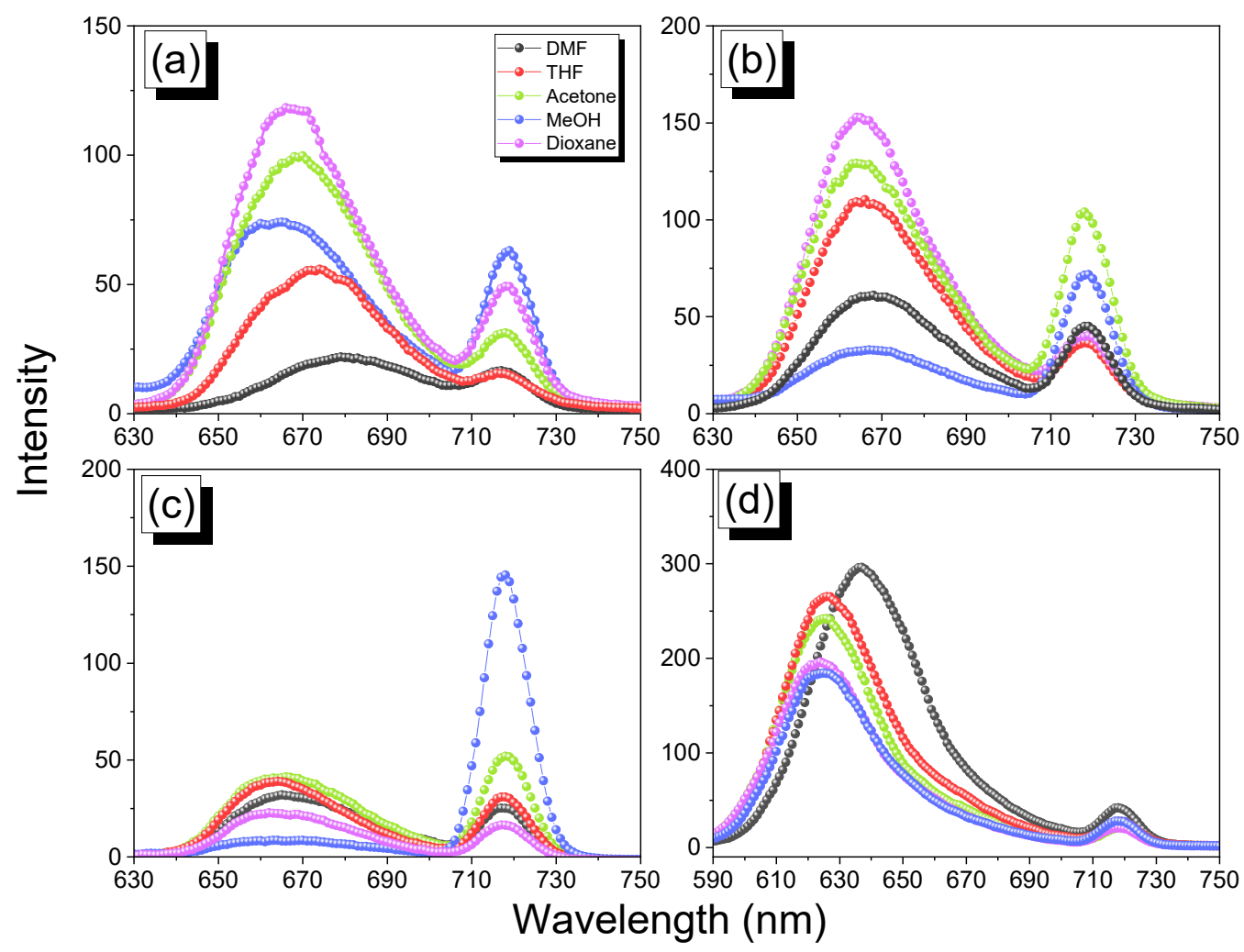

Figure 9. PL spectra of (a) TAPP, (b) Por-BZ, (c) the Por-BZ/Ni complex, and (d) the Por-BZ/Zn complex.

\subsection{Thermal ROP of Por-BZ/Metal Complex}

We used DSC analyses to monitor the thermal ROP behavior of Por-BZ/Ni and Por$\mathrm{BZ} / \mathrm{Zn}$ complexes after their thermal curing for $2 \mathrm{~h}$ at temperatures of 150,180 , and $210^{\circ} \mathrm{C}$, respectively. Figure $10 \mathrm{a}, \mathrm{c}$ reveal that the thermal curing peak temperatures of uncured Por-BZ/Ni and Por-BZ/Zn complexes were centered at 241 and $231^{\circ} \mathrm{C}$, respectively, as mentioned in our discussion of Figure 5A. Similar to the behavior of pure Por-BZ, the exothermic enthalpies of both the Por-BZ/Ni and Por-BZ/Zn complexes decreased with the increase in temperature, and disappeared completely after thermal treatment at $210^{\circ} \mathrm{C}$. Although the thermal curing behavior was consistent with that of the pure Por-BZ under the same thermal curing conditions, which was much lower than that of pure Por-BZ monomer, suggesting that the presence of the $\mathrm{Ni}$ and $\mathrm{Zn}$ ions assisted the ring-opening procedure. We used FTIR to study the thermal curing polymerization behavior of Por$\mathrm{BZ} / \mathrm{Ni}$ and Por-BZ/Zn complexes after thermal polymerization at different temperatures (Figure 10b,d). Similar to Figure 3B, when the thermal polymerization temperature was increased, the characteristic absorption bands of the oxazine structure at 1222 and $948 \mathrm{~cm}^{-1}$ gradually decreased, and disappeared completely as the thermal curing temperature was only $210^{\circ} \mathrm{C}$, compared with $240{ }^{\circ} \mathrm{C}$ for the pure Por-BZ monomer, again suggesting that the $\mathrm{Ni}$ (Figure 10b) and $\mathrm{Zn}$ (Figure 10d) ions assisted the ROP, and implying the formation of highly cross-linked poly(Por-BZ/metal) complexes. Figure 11a displays the results of TGA analyses of pure Por-BZ and the Por-BZ/Ni and Por-BZ/Zn complexes after thermal ROP at $210{ }^{\circ} \mathrm{C}$. The values of $T_{\mathrm{d} 10}$ and the char yields increased to $458{ }^{\circ} \mathrm{C}$ and $64.3 \mathrm{wt} \%$, respectively, for the poly(Por-BZ/Ni) complex and to $465^{\circ} \mathrm{C}$ and $71.1 \mathrm{wt} \%$, respectively, for the poly(Por-BZ/Zn) complex, when compared with those of the pure poly(Por-BZ) $\left(453^{\circ} \mathrm{C}\right.$ and $61.5 \mathrm{wt} \%$, respectively). Figure $9 \mathrm{~B}$ displays these three corresponding exothermic peaks after thermal ROP at $210^{\circ} \mathrm{C}$; the first exothermic peaks disappeared for both the Por-BZ/Ni and Por-BZ/Zn complexes, indicating that the $\mathrm{Ni}$ and $\mathrm{Zn}$ ions not only facilitated the ROP of Por-BZ, but also enhanced the thermal stability and char yield significantly based on 
TGA analyses. According to the DSC, FTIR spectral, and TGA analyses, the coordination ability to the porphyrin structure of the $\mathrm{Zn}$ ion appeared to be stronger than that of the $\mathrm{Ni}$ ion, as has been discussed widely in previous reports [49], resulting in a lower ROP temperature and a higher thermal stability.
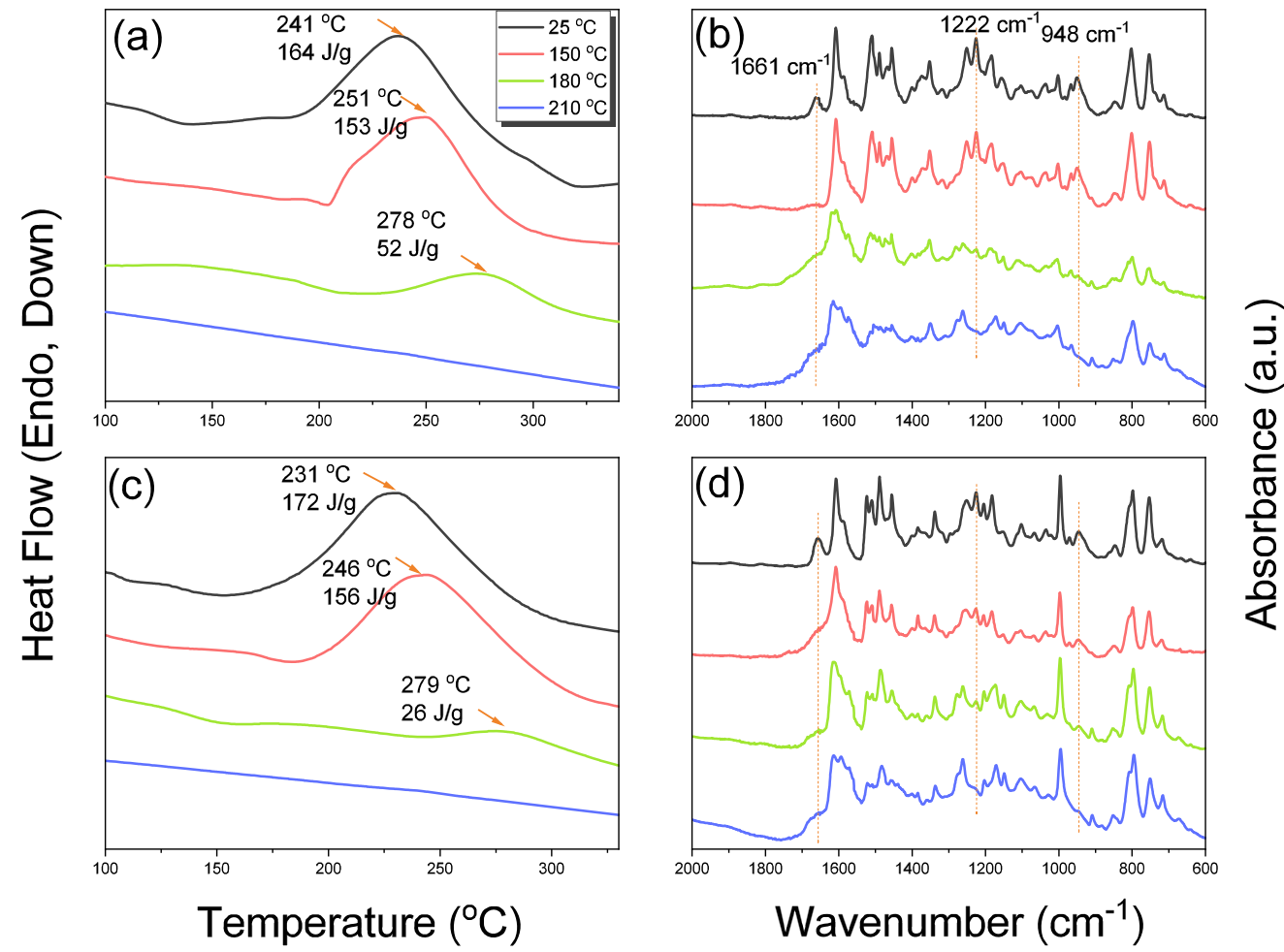

Figure 10. DSC and FTIR spectral analyses of $(\mathbf{a}, \mathbf{b})$ Por-BZ/Ni and $(\mathbf{c}, \mathbf{d})$ Por-BZ/Zn complexes after thermal $\mathrm{ROP}$ at various temperatures.

(a)

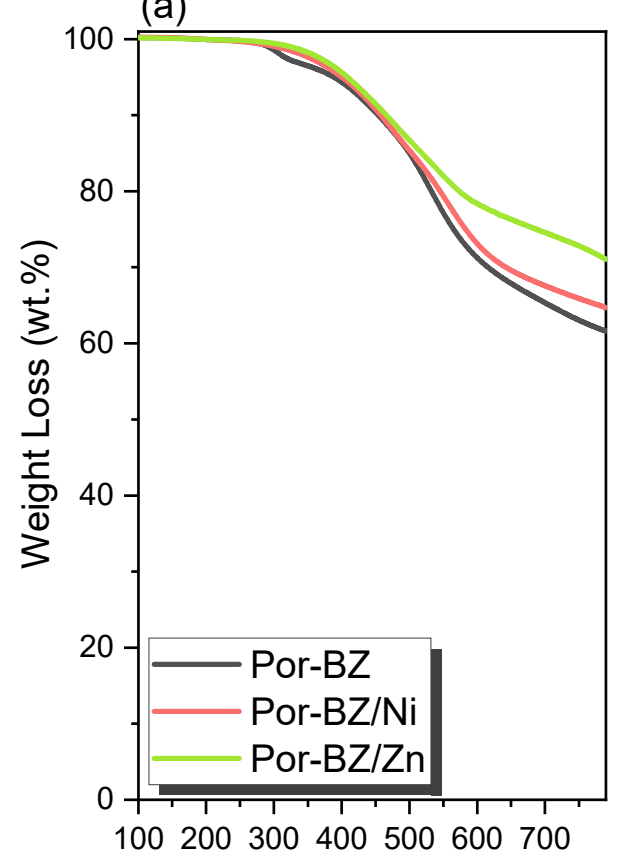

(b)
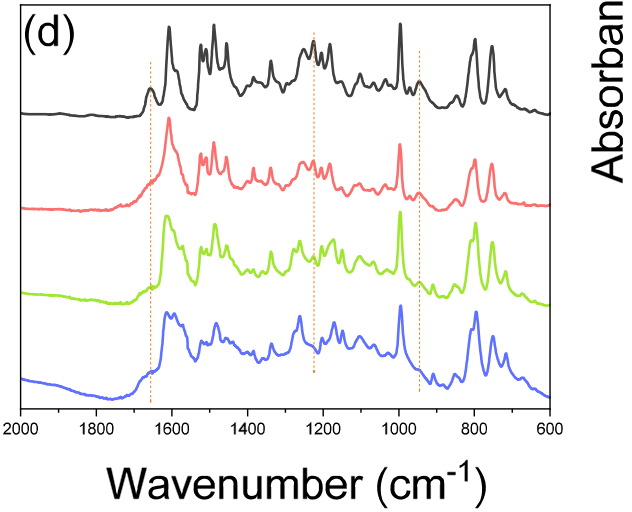

Temperature $\left({ }^{\circ} \mathrm{C}\right)$

Figure 11. (a) TGA and (b) corresponding second-derivative curves based on TGA analyses of the Por-BZ monomer and the Por-BZ/Ni and Por-BZ/Zn complexes after thermal ROP at $210{ }^{\circ} \mathrm{C}$. 


\section{Conclusions}

We synthesized the new porphyrin-functionalized BZ monomer from the reaction of TAPP with salicylaldehyde, and the subsequent reduction of the Schiff base of Por-Sa with $\mathrm{CH}_{2} \mathrm{O}$, with characterization based on NMR and FTIR spectroscopy. Because of the rigid porphyrin structure, the resulting poly(Por-BZ) displayed excellent thermal stability, with the thermal exothermic curing peak of Por-BZ shifted to $314^{\circ} \mathrm{C}$. After the addition of $\mathrm{Ni}$ and $\mathrm{Zn}$ ions, however, this thermal exothermic curing peak shifted significantly to 241 and $231{ }^{\circ} \mathrm{C}$, respectively, suggesting that these metal ions accelerated the ROP of the Por-BZ unit. Furthermore, the thermal stability of these Por-BZ/metal complexes improved, compared with that of the pure Por-BZ, after thermal polymerization.

Supplementary Materials: The following are available online at https:/ /www.mdpi.com/article/10 .3390/polym14030449/s1, Scheme S1: the chemical structure of Por-BZ and their thermal polymerization, Figure S1: PL profile of TAPP and Por-BZ/Zn complex.

Author Contributions: G.Z. and A.F.M.E.-M. conceived of and designed the project; G.Z., A.F.M.E.-M., L.R.A. and B.M.M. performed the experiments; all authors analyzed the data; G.Z., S.-W.K. and K.C.-W.W., writing - original draft preparation and editing; S.A.-S. performed the TGA and IR experiments; S.-W.K. and K.C.-W.W., supervision. All the authors discussed the results and wrote the manuscript. All authors have read and agreed to the published version of the manuscript.

Funding: This project received funding from by the Ministry of Science and Technology, Taiwan, under Contracts MOST 109-2221-E-110-067-MY3, 110-2628-E-002-014, 110-2124-M-002-013. The authors (S.A.-S) thank to Princess Nourah bint Abdulrahman University, Researchers Supporting Project Number (PNURSP2022R58) Princess Nourah bint Abdulrahman University, Riyadh, Saudi Arabia.

Institutional Review Board Statement: Not applicable.

Informed Consent Statement: Not applicable.

Data Availability Statement: Not applicable.

Conflicts of Interest: The authors declare no conflict of interest. The funders had no role in the design of the study; in the collection, analyses, or interpretation of data; in the writing of the manuscript; or in the decision to publish the results.

\section{References}

1. Yadav, N.; Monisha, M.; Niranjan, R.; Dubey, A.; Patil, S.; Priyadarshini, R.; Lochab, B. Antibacterial performance of fully biobased chitosan-grafted-polybenzoxazine films: Elaboration and properties of released material. Carbohydr. Polym. 2021, 254, 117296. [CrossRef]

2. Lyu, Y.; Rachita, E.; Pogharian, N.; Froimowicz, P.; Ishida, H. Electronic effects of asymmetric and meta-alkoxy substituents on the polymerization behavior of bis-benzoxazines. Polym. Chem. 2020, 11, 800-809. [CrossRef]

3. Zhang, X.; Mohamed, M.G.; Xin, Z.; Kuo, S.W. A tetraphenylethylene-functionalized benzoxazine and copper(II) acetylacetonate form a high-performance polybenzoxazine. Polymer 2020, 201, 122552. [CrossRef]

4. Wu, J.J.; Zhao, C.X.; Li, Y.T.; Li, H.; Xiang, D.; Sun, Z.M.; Li, X. Properties of bio-based thermosetting composites synthesized from epoxidized soybean oil and azo-cardanol benzoxazine. J. Polym. Res. 2021, 28, 77. [CrossRef]

5. Ohashi, S.; Rachita, E.; Baxley, S.; Zhou, J.; Erlichman, A.; Ishida, H. The first observation on polymerization of 1,3-benzothiazines: Synthesis of mono- and bis-thiazine monomers and thermal properties of their polymers. Polym. Chem. 2021, 12, 379-388. [CrossRef]

6. Zhang, K.; Yu, X.; Kuo, S.W. Outstanding dielectric and thermal properties of main chain-type poly(benzoxazine-co-imide-cosiloxane)-based cross-linked networks. Polym. Chem. 2019, 10, 2387-2396. [CrossRef]

7. Abuzeid, H.R.; EL-Mahdy, A.F.M.; Ahmed, M.M.M.; Kuo, S.W. Triazine-functionalized covalent benzoxazine framework for direct synthesis of N-doped microporous carbon. Polym. Chem. 2019, 10, 6010-6020. [CrossRef]

8. Kolanadiyil, S.N.; Minami, M.; Endo, T. Implementation of meta-Positioning in Tetrafunctional Benzoxazines: Synthesis, Properties, and Differences in the Polymerized Structure. Macromolecules 2020, 53, 6866-6886. [CrossRef]

9. Hao, B.; Han, L.; Liu, Y.; Zhang, K. An apigenin-based bio-benzoxazine with three polymerizable functionalities: Sustainable synthesis, thermal latent polymerization, and excellent thermal properties of its thermosets. Polym. Chem. 2020, 11, 5800-5809. [CrossRef]

10. Deliballi, Z.; Kiskan, B.; Yagci, Y. Advanced Polymers from Simple Benzoxazines and Phenols by Ring-Opening Addition Reactions. Macromolecules 2020, 53, 2354-2361. [CrossRef] 
11. El-Mahdy, A.F.; Lin, F.W.; Su, W.H.; Chen, T.; Kuo, S.W. Photoresponsive azobenzene materials based on pyridine-functionalized benzoxazines as surface relief gratings. ACS Appl. Polym. Mater. 2019, 2, 791-804. [CrossRef]

12. Li, X.; Liu, Y.; Chen, H.; Li, H. Benzoxazine monomers containing triphenylimidazole: Polymerization of monomers and properties of polybenzoxazines. Eur. Polym. J. 2019, 121, 109347. [CrossRef]

13. Tavernier, R.; Granado, L.; Foyer, G.; David, G.; Caillol, S. Formaldehyde-Free Polybenzoxazines for High Performance Thermosets. Macromolecules 2020, 53, 2557-2567. [CrossRef]

14. Wang, C.F.; Su, Y.C.; Kuo, S.W.; Huang, C.F.; Sheen, Y.C.; Chang, F.C. Low-Surface-Free-Energy Materials Based on Polybenzoxazines. Angew. Chem. Int. Ed. 2006, 118, 2306-2309. [CrossRef]

15. Sawaryn, C.; Landfester, K.; Taden, A. Benzoxazine Miniemulsions Stabilized with Polymerizable Nonionic Benzoxazine Surfactants. Macromolecules 2010, 43, 8933-8941. [CrossRef]

16. Alhwaige, A.A.; Agag, T.; Ishida, H.; Qutubuddin, S. Chitosan Biobased Polybenzoxazine Cross-Linked Films: Preparation in Aqueous Media and Synergistic Improvements in Thermal and Mechanical Properties. Biomacromolecules 2013, 14, $1806-1815$. [CrossRef]

17. Chen, C.; Cao, Y.; Lu, X.; Yao, H.; Xin, Z. Copolymer of eugenol-based and pyrogallol-based benzoxazines: Low curing temperature and enhanced corrosion resistance. Colloids Surf. A Physicochem. Eng. 2021, 609, 125605. [CrossRef]

18. Yang, R.; Han, M.; Hao, B.; Zhang, K. Biobased high-performance tri-furan functional bis-benzoxazine resin derived from renewable guaiacol, furfural and furfurylamine. Eur. Polym. J. 2020, 131, 109706. [CrossRef]

19. Yu, X.; Zhang, K. Studies on the isomeric effect of nitrile functionality on the polymerization and thermal properties of orthonorbornene-based benzoxazine resins. J. Polym. Res. 2020, 27, 130. [CrossRef]

20. Mohamed, M.G.; Chen, T.C.; Kuo, S.W. Solid-State Chemical Transformations to Enhance Gas Capture in Benzoxazine-Linked Conjugated Microporous Polymers. Macromolecules 2021, 54, 5866-5877. [CrossRef]

21. Liu, Y.; Sheng, W.; Yin, R.; Zhang, K. Propargylamine: An attractive amine source for designing high-performance benzoxazine resins with low polymerization temperatures. Polym. Chem. 2021, 12, 6694-6704. [CrossRef]

22. Abuzeid, H.R.; EL-Mahdy, A.F.M.; Kuo, S.W. Covalent Organic Frameworks: Design Principles, Synthetic Strategies, and Diverse Applications. Giant 2021, 6, 100054. [CrossRef]

23. Samy, M.M.; Mohamed, M.G.; Mansoure, T.H.; Meng, T.S.; Khan, M.A.R.; Liaw, C.C.; Kuo, S.W. Solid state chemical transformations through ring-opening polymerization of ferrocene-based conjugated microporous polymers in host-guest complexes with benzoxazine-linked cyclodextrin. J. Taiwan Inst. Chem. Eng. 2022, 132, 104110. [CrossRef]

24. Tavernier, R.; Granado, L.; Foyer, G.; David, G.; Caillol, S. Aromatic dialdehyde-based bisbenzoxazines: The influence of relative position of oxazine rings. Polymer 2021, 216, 123270. [CrossRef]

25. Ohara, M.; Yoshimoto, K.; Kawauchi, T.; Takeichi, T. Synthesis of high-molecular-weight benzoxazines having azomethine linkages in the main-chain and the properties of their thermosetting resins. Polymer 2020, 202, 122668. [CrossRef]

26. Salum, M.L.; Iguchi, D.; Arza, C.R.; Han, L.; Ishida, H.; Froimowicz, P. Making Benzoxazines Greener: Design, Synthesis, and Polymerization of a Biobased Benzoxazine Fulfilling Two Principles of Green Chemistry. ACS Sustain. Chem. Eng. 2018, 6 , 13096-13106. [CrossRef]

27. Mohamed, M.G.; Kuo, S.W. Crown Ether-Functionalized Polybenzoxazine for Metal Ion Adsorption. Macromolecules 2020, 53, 2420-2429. [CrossRef]

28. EL-Mahdy, A.F.M.; Liu, T.E.; Kuo, S.W. Direct synthesis of nitrogen-doped mesoporous carbons from triazine-functionalized resol for $\mathrm{CO}_{2}$ uptake and highly efficient removal of dyes. J. Hazard. Mater. 2020, 391, 122163. [CrossRef]

29. EL-Mahdy, A.F.M.; Yu, T.C.; Kuo, S.W. Synthesis of multiple heteroatom-doped mesoporous carbon/silica composites for supercapacitors. Chem. Eng. J. 2021, 414, 128796. [CrossRef]

30. El-Mahdy, A.F.M.; Kuo, S.W. Direct synthesis of poly (benzoxazine imide) from an ortho-benzoxazine: Its thermal conversion to highly cross-linked polybenzoxazole and blending with poly (4-vinylphenol). Poly. Chem. 2018, 9, 1815-1826. [CrossRef]

31. Coban, Z.G.; Yagci, Y.; Kiskan, B. Catalyzing the Ring-Opening Polymerization of 1,3-Benzoxazines via Thioamide from Renewable Sources. ACS Appl. Polym. Mater. 2021, 3, 4203-4212. [CrossRef]

32. Mohamed, M.G.; Kuo, S.W. Functional Silica and Carbon Nanocomposites Based on Polybenzoxazines. Macromol. Chem. Phys. 2019, 220, 1800306. [CrossRef]

33. Samy, M.M.; Mohamed, M.G.; Kuo, S.W. Pyrene-functionalized tetraphenylethylene polybenzoxazine for dispersing single-walled carbon nanotubes and energy storage. Compos. Sci. Technol. 2020, 199, 108360

34. Martinez, V.G.; Gude, M.R.; Calvo, S.; Urena, A. Enhancing an Aerospace Grade Benzoxazine Resin by Means of Graphene Nanoplatelets Addition. Polymers 2021, 13, 2544. [CrossRef] [PubMed]

35. Kumaran, R.; Kumar, A.V.; Ramaprabhu, S.; Subramanian, V. Absorption-enhanced EMI shielding using silver decorated threedimensional porous architected reduced graphene oxide in polybenzoxazine composites. New J. Chem. 2021, 45, 16939-16948 [CrossRef]

36. Lin, C.H.; Chen, W.B.; Whang, W.T.; Chen, C.H. Characteristics of Thermosetting Polymer Nanocomposites: Siloxane-ImideContaining Benzoxazine with Silsesquioxane Epoxy Resins. Polymers 2020, 12, 2510. [CrossRef]

37. Zhang, S.; Lan, T.; Ren, D.; Liu, X.; Ran, Q. Tuning the polymerization sequence of alkynyl-functionalized benzoxazine: Application as precursor for efficient magnetic EMI shielding materials. J. Mater. Sci. 2021, 56, 10691. [CrossRef] 
38. Mohamed, M.G.; Kuo, S.W. Functional Polyimide/Polyhedral Oligomeric Silsesquioxane Nanocomposites. Polymers 2019, 11, 26. [CrossRef]

39. Prasomsin, W.; Parnklang, T.; Sapcharoenkun, C.; Tiptipakorn, S.; Rimdusit, S. Multiwalled Carbon Nanotube Reinforced Bio-Based Benzoxazine/Epoxy Composites with NIR-Laser Stimulated Shape Memory Effects. Nanomaterials 2019,9 , 881. [CrossRef]

40. Ahn, D.; Choi, H.J.; Kim, H.D.; Yeo, S.Y. Properties of Conductive Polyacrylonitrile Fibers Prepared by Using Benzoxazine Modified Carbon Black. Polymers 2020, 12, 179. [CrossRef] [PubMed]

41. Arivalagan, V.; Stephen, L.D.; Meera, M.; Gunasekaran, S.G. Carbazole terminal phenylene core imine skeletal nanosilica reinforced polybenzoxazine (nSiO2O2/PBZ) hybrid nanocomposites. J. Polym. Res. 2021, 28, 381. [CrossRef]

42. Auwärter, W.; Seufert, K.; Bischoff, F.; Ecija, D.; Vijayaraghavan, S.; Joshi, S.; Klappenberger, F.; Samudrala, N.; Barth, J.V. A surface-anchored molecular four-level conductance switch based on single proton transfer. Nat. Nanotechnol. $2012,7,41$. [CrossRef] [PubMed]

43. Spitaleri, L.; Gangemi, C.M.A.; Purrello, R.; Nicotra, G.; Trusso Sfrazzetto, G.; Casella, G.; Casarin, M.; Gulino, A. Covalently Conjugated Gold-Porphyrin Nanostructures. Nanomaterials 2020, 10, 1644. [CrossRef] [PubMed]

44. Cui, F.Z.; Liu, Z.; Ma, D.L.; Liu, L.; Haung, T.; Zhang, P.; Tan, D.; Wang, F.; Jiang, G.F.; Wu, Y. Polyarylimide and porphyrin based polymer microspheres for zinc ion hybrid capacitors. Chem. Eng. J. 2021, 405, 127038. [CrossRef]

45. Mukherjee, G.; Thote, J.; Aiyappa, H.B.; Kandambeth, S.; Banerjee, S.; Vanka, K.; Banerjee, R. A porous porphyrin organic polymer (PPOP) for visible light triggered hydrogen production. Chem. Commun. 2017, 53, 4461-4464. [CrossRef] [PubMed]

46. Zhang, H.; Xu, Z.; Mao, Y.; Zhang, Y.; Li, Y.; Lao, J.; Wang, L. Integrating Porphyrinic Metal-Organic Frameworks in Nanofibrous Carrier for Photodynamic Antimicrobial Application. Polymers 2021, 13, 3942. [CrossRef] [PubMed]

47. Ognibene, G.; Gangemi, C.M.A.; Spitaleri, L.; Gulino, A.; Purrello, R.; Cicala, G.; Fragalà, M.E. Role of the surface composition of the polyethersulfone-TiiP-H2T4 fibers on lead removal: From electrostatic to coordinative binding. J. Mater. Sci. 2019, $54,8023$. [CrossRef]

48. Li, D.; Fang, Y.; Zhang, X. Bacterial Detection and Elimination Using a Dual-Functional Porphyrin-Based Porous Organic Polymer with Peroxidase-Like and High Near-Infrared-Light-Enhanced Antibacterial Activity. ACS Appl. Mater. Interfaces 2020, 12, 8989-8999. [CrossRef]

49. Chen, Y.; Fang, Y.; Yu, J.; Gao, W.; Zhao, H.; Zhang, X. A silsesquioxane-porphyrin-based porous organic polymer as a highly efficient and recyclable absorbent for wastewater treatment. J. Hazard. Mater. 2021, 406, 124769. [CrossRef]

50. Li, M.; Zhao, H.; Lu, Z.Y. Porphyrin-based porous organic polymer, Py-POP, as a multifunctional platform for efficient selective adsorption and photocatalytic degradation of cationic dyes. Microporous Mesoporous Mater. 2020, 292, 109774. [CrossRef]

51. EL-Mahdy, A.F.M.; Zakaria, M.B.; Wang, H.X.; Chen, T.; Yamauchi, Y.; Kuo, S.W. Heteroporous bifluorenylidene-based covalent organic frameworks displaying exceptional dye adsorption behavior and high energy storage. J. Mater. Chem. A 2020, 8 , 25148-25155. [CrossRef]

52. Bain-Ackerman, M.J.; Lavallee, D.K. Kinetics of Metal-Ion Complexation with N-Methyltetraphenylporphyrin. Evidence Concerninga General Mechanism of Porphyrin Metalation. Inorg. Chem. 1979, 18, 3358-3364. [CrossRef]

53. Angelis, F.D.; Fantacci, S.; Sgamellotti, A.; Pizzotti, M.; Tessore, F.; Biroli, A.O. Time-dependent and coupled-perturbed DFT and $\mathrm{HF}$ investigations on the absorption spectrum and non-linear optical properties of push-pull $\mathrm{M}(\mathrm{II})$-porphyrin complexes (M = Zn, Cu, Ni). Chem. Phy. Lett. 2007, 447, 10-15. [CrossRef]

54. Torre, G.; Vazquez, P.; Lopez, F.A.; Torres, T. Role of Structural Factors in the Nonlinear Optical Properties of Phthalocyanines and Related Compounds. Chem. Rev. 2004, 104, 3723-3750. [CrossRef] [PubMed]

55. Uttamlal, M.; Holmes-Smith, A.S. The excitation wavelength dependent fluorescence of porphyrins. Chem. Phys. Lett. 2008, 54, 223. [CrossRef]

56. Gangemi, C.M.A.; Iudici, M.; Spitaleri, L.; Randazzo, R.; Gaeta, M.; D’Urso, A.; Gulino, A.; Purrello, R.; Fragalà, M.E. Polyethersulfone Mats Functionalized with Porphyrin for Removal of Para-nitroaniline from Aqueous Solution. Molecules 2019, $24,3344$. [CrossRef]

57. EL-Mahdy, A.F.M.; Lai, M.Y.; Kuo, S.W. Highly fluorescent covalent organic framework as hydrogen chloride sensor: Roles of schiff base bonding and $\pi$-stacking. J. Mater. Chem. C 2020, 8, 9520-9528. [CrossRef]

58. Wu, J.H.; Chen, W.C.; Liou, G.S. Triphenylamine-based luminogens and fluorescent polyimides: Effects of functional groups and substituents on photophysical behaviors. Polym. Chem. 2016, 7, 1569-1576. [CrossRef]

59. EL-Mahdy, A.F.M.; Elewa, A.M.; Hung, S.W.; Chou, H.H.; Kuo, S.W. Dual-Function Fluorescent Covalent Organic Frameworks: $\mathrm{HCl}$ Sensing and Photocatalytic $\mathrm{H}_{2}$ Evolution from Water. Adv. Opt. Mater. 2020, 8, 2000641. [CrossRef]

60. EL-Mahdy, A.F.M.; Young, C.; Kim, J.; You, J.; Yamauchi, Y.; Kuo, S.W. Hollow Microspherical and Microtubular [3 + 3] CarbazoleBased Covalent Organic Frameworks and Their Gas and Energy Storage Applications. ACS Appl. Mater. Interface 2019, 11, 9343-9354. [CrossRef]

61. Mohamed, M.G.; EL-Mahdy, A.F.M.; Kotp, M.G.; Kuo, S.W. Advances in porous organic polymers: Syntheses, structures, and diverse applications. Mater. Adv. 2022, 3, 707-733. [CrossRef]

62. Annalinda, C.; Giuseppe, M.; Maria, E.F.; Luca, S.; Antonino, G. Conjugated Gold-Porphyrin Monolayers Assembled on Inorganic Surfaces. Chem. Eur. J. 2017, 23, 14937-14943. [CrossRef] 